\title{
New Fossil Hominids from Laetolil, Tanzania
}

\author{
TIM D. WHITE \\ University of Michigan, Department of Anthropology, \\ Ann Arbor, Michigan 48109
}

\section{KEY WORDS Fossil hominid · Dentition ' Mandible - Tanzania}

\begin{abstract}
New fossil hominid specimens from the Laetolil fossil locality in Tanzania are described. The material includes mandibles and teeth derived from reliably-dated deposits of Pliocene age. Preliminary descriptions, measurements and illustrations are presented.
\end{abstract}

This paper furnishes a preliminary description of hominid remains recovered from the Laetolil fossil locality in Tanzania. The specimens were found during 1974 and 1975 palaeontological investigations of the Laetolil site under the direction of Doctor M. D. Leakey. A preliminary assessment of the stratigraphy, fauna and dating of the Laetolil deposits appears in Leakey, Hay, Curtis, Drake, Jackes and White (76). Provisional stratigraphic correlation and dating place the hominids described here between volcanic strata dated to 3.59 and 3.77 M.Y.A.

The specimens represent original surface finds, but subsequent excavations have recovered additional in situ material represented by Laetolil hominids (L.H.-) 2, 3 and 6. All of the specimens besides L.H.-7 and L.H.-8 retain patches of characteristic Laetolil matrix, establishing contemporaneity of these fossils and the sediments from which they derive.

These descriptions, measurements and illustrations are presented to provide other workers with an adequate background from which to interpret the new material, following the procedure and example of Leakey, Mungai and Walker (71). Formal taxonomic and phylogenetic assessment are not within the scope of this description and must await detailed study.

The descriptions adhere to the anatomical terminology of Weidenreich (36) for the mandible and Robinson (56) as modified by Tobias ('67) for the dentition. Measurements are taken as defined in the text and are applied consistently. A low-power binocular microscope was used where noted.

\section{DESCRIPTIONS}

All measurements in millimeters.

LAETOLIL HOMINID 1: Locality 1 (plate 5A, table 1)

Specimen consists of: RP4 fragment.

Preservation: The lingual two-thirds of the crown remain intact. The root is broken and the cervical line missing. The crown is covered with micropitting, probably chemical in origin, which intensifies buccally to largely destroy the buccal crown aspect.

Morphology: Upper fourth premolar: Crown shape is judged to have been an elongate oval, widest lingually. There are major buccal and lingual cusps of estimated equal area, the apex of the latter placed strongly mesiad of the buccolingual crown axis. Rounded, polished wear is seen on the lingual cusp. Partially damaged, flat interprox imal facets for $P^{3}$ and $M^{1}$ occupy mesial and distal crown faces. The buccal cusp probably reached a higher elevation above the crown base than the lingual. The lingual cusp presents a rounded, distally sloping ridge and a smooth, sloping lingual crown face. Primary fissuration is $\mathrm{H}$-shaped, with mesiobuccal arm set off by a sharp crest to form a deep, pitlike anterior fovea. The central fissure is deep and terminates in strong distobuccal and weaker distolingual arms which divide to define a small distolingually placed talon capsule. Secondary fissuration is not complex, consisting of a pair of transverse arms perpendicular to the central fissure near midcrown level. Striated perikymata are visible on the better perserved distolingual crown face. Enamel imperfections include a micropit located just above the interproximal facet for $\mathbf{P}^{3}$, and a larger, 2.0 diameter scalloped pit placed just below the $M^{1}$ contact facet.

LAETOLIL HOMINID 2: Locality 3 (plate 1A-G, tables 2, 3)

Specimen consists of: Mandible with intact crowns $R+L d M_{2}$; unerupted crowns $R+L I_{1}, \bar{C}$, $\mathbf{P}_{3}$; damaged crowns $\mathbf{R}+\mathrm{L} d \bar{C}, \mathbf{d M}_{1}, M_{1}$; broken roots $\mathrm{R}+\mathrm{L} \mathrm{dI}_{1}, \mathrm{dI}_{2}$.

Preservation:

I. The mandible. The mandibular corpus has suffered extensive damage. The internal alveolar margin is intact anterior to right and left $d M_{1}$, the external margin preserved buccal to right and left $d M_{2}$ and right $M_{1}$. The basal contour is intact 
TABLE 1

Dental measurements ${ }^{1}$

\begin{tabular}{|c|c|c|c|c|c|}
\hline & $P^{3}$ & $\mathbf{P}^{4}$ & $\mathbf{M}^{1}$ & $M^{2}$ & $M^{3}$ \\
\hline $\begin{array}{l}\text { LAETOLIL HOM. } \\
1(\mathrm{rt} .) \mathrm{M} / \mathrm{D} \\
\quad \text { B/L }\end{array}$ & - & $\stackrel{9,0}{\mathrm{X}}$ & - & - & 二 \\
\hline $\begin{array}{c}7 \text { (1t.) } M / D \\
B / L\end{array}$ & 二 & 二 & $\begin{array}{l}\mathrm{X} \\
\mathrm{X}\end{array}$ & $=$ & - \\
\hline $8(\mathrm{rt}.) \mathrm{M} / \mathrm{D}$ & - & - & - & $\begin{array}{c}11.9 \\
(12.9)\end{array}$ & $\begin{array}{c}11.4 \\
(11.6)\end{array}$ \\
\hline $\mathrm{B} / \mathrm{L}$ & - & - & - & $(15.0)$ & $(14.0)$ \\
\hline 11 (lt.) M/D & - & 二 & $\begin{array}{l}12.7 \\
15.0\end{array}$ & - & - \\
\hline $12 \underset{\mathrm{B} / \mathrm{L}}{(1 \mathrm{t})} \mathrm{M} / \mathrm{D}$ & - & - & 二 & $=$ & $\begin{array}{l}\mathrm{x} \\
\mathrm{x}\end{array}$ \\
\hline
\end{tabular}

1 Dental measurements taken to 0.1 accuracy with sliding vernier caliper, $X$ : broken or worn; present; ( ): iestimate. The estimated corrections for interproximal attrition or slight damage included in brackets are considered within \pm 0.5 of unworn or undamaged dimension. If ( + ) included, measure can only be greater but remains within 0.5 .

Mesiodistal diameter (M/D): taken parallel to the crown base as the absolute length along mesiodistal crown axis as the tooth normally rests in the dental arcade. Generally from mesial to distal interproximal contact facets.

Buccolingual diameter $(B / L)$ : taken parallel to the plane of the crown base as a maximum distance between buccal and lingual crown faces on an axis perpendicular to that of the M/D measurement.

Cervico-incisal height (C/I); taken for unworn anterior teeth as crown height from incisal margin to labial line along central crown axis.

for a distance of about 3 to the right of the midline, elsewhere it is missing. The lateral right corpus is best preserved, the root of the ramus damaged. Cortical bone on right and left sides and in the anterior region is broken to expose elements of the unerupted permanent dentition. The specimen was recovered in two major fragments, right and left halves. The midline break displays matrix be. tween symphyseal halves once in contact. The natural mold of the right $I_{1}$ in the left symphyseal matrix surface allows accurate placement of right and left corpora in the pre-fossilization position. This is anatomically unsatisfactory because it is apparent from the $1 \mathrm{~mm}$ to $3 \mathrm{~mm}$-wide crack in the posterior symphysis that the placement of right and left tooth rows and hence the overall shape of the dental arcade has been affected. The bimolar distance has been increased slightly by matrix wedging at the symphysis. Correction of the displacement by removal of intervening matrix may be possible in the future. Matrix wedging has also forced the distal right $\mathrm{dI}_{1}$ root anteriorly, matrix filling the space between this root and the labial face of the unerupted right $I_{1}$. The remainder of the dentition occupies anatomically correct posi tion.

II. The dentition. Only the broken roots of the deciduous incisors remain. The left dC crown is missing except for a flake of labial enamel. The right dC preserves a fairly intact dentine core but only small patches of original enamel surface remain. Both $\mathrm{dM}_{1}$ 's are damaged, the right lacking enamel on its lingual aspect, and the left on the buccal surface of the distobuccal cusp (hypoconid) and lingual surface of the mesiolingual cusp (metaconid). Both sides show roughened mesiolingual enamel surfaces indicative of mild chemical erosion.

The $\mathrm{dM}_{2}$ crowns are essentially intact. Chem. ical erosion has etched the enamel surface of the right crown, but the left largely retains intact enamel. Both $M_{1}$ 's are damaged. The left suffers loss of its mesiolingual quadrant and slight expansion along a mesiodistally directed crack. The right crown is complete, but a buccolingually directed crack 0.4-wide traverses the mesiobuccal cusp (protoconid) and metaconid, displacing the distal portion of the tooth about 1 superiorly. The enamel surface of the right $M_{1}$ is damaged as the right $\mathbf{d M}_{2}$. The unerupted, incomplete left permanent canine crown is cracked axially.

Morphology:

I. The mandible.

A. Lateral aspect. The better preserved right corpus displays posterior convergence of basal and occlusal margins from their widest separation at the symphysis. The resultant anterior deepening of the mandible is exaggerated by loss of the base (basis mandibulae) below the $\mathbf{M}_{1}$. The corpus dis plays a rounded lateral profile in its intact parts. The alveolar margin lateral to $\mathrm{d}_{2}$ and $\mathrm{M}_{1}$ is sharp and straight, sweeping posterosuperiorly to obscure the base of the $M_{1}$ in true lateral aspect. Damage below the anterior $d M_{1}$ reveals the buccal face of the unerupted $P_{3}$ whose apex lies between the $d_{M}$ roots. The broken corpus edge around this unerupted crown is sufficiently preserved to in dicate strong swelling opposite the unerupted premolar prior to breakage. The base of the incompletely formed permanent canine is exposed about 18 below the alveolar margin at $\mathrm{d}_{1} / \mathrm{d}_{\mathrm{z}}$.

The left corpus preserves little cortical bone. Breakage reveals a wealth of detail about the erupt 
ing permanent dentition. The $\mathbf{P}_{3}$ crown so exposed lacks root development and is set between the divergent $\mathrm{d}_{1}$ roots, its apex probably at the level of the alveolar margin and its base oriented as the antimere. The broken mesial root apex of $\mathrm{dM}_{2}$ is in close contact with the distal $P_{3}$ crown. Immediately below the unerupted $\mathrm{P}_{3}$ and separated from it by a thin bony wall is the permanent canine crown. This is not fully formed and bears no root. It is longitudinally oriented at about $30^{\circ}$ to the occlusal plane, its apex immediately posterior to the terminal $\mathrm{d} \overline{\mathrm{C}}$ root about 14 below the alveolar margin. Its crypt occupies the very base of the corpus.

B. Anterior aspect. Much cortical bone is missing, exposing deciduous anterior tooth roots and unerupted $I_{1}$ crowns. The cortex fragment on the right below the $\mathrm{dI}_{1}$ and $\mathrm{d} \overline{\mathrm{C}}$ roots is smoothly convex with little relief. It was apparently interrupted by swellings over the unerupted $I_{1}$ and $\overline{\mathrm{C}}$ crowns. A small patch of alveolar bone remains across the midline. The interalveolar septum here is intact, with the anatomic point intradentale (ID) preserved. The anterior alveolar portion bears a midline effect in the form of a fine, vertical crack occupying a sharp midline ridge. Lateral to the ridge and midline fissure the bone is perforated by microforamina.

The vertical crown axes of the unerupted $I_{1}$ 's converge superiorly, the left crown set slightly more anteriorly. The labial enamel line of the right crown is measured directly as 22.9 below the midline alveolar margin. The deciduous incisor roots diverge posteroinferiorly.

C. Symphyseal aspect. The natural left sym. physeal section displays exposed bone in the area of the superior transverse torus (tome transiersus superior), but no other midline bone is visible. The impression of the unerupted right $I_{1}$ crown is preserved in the matrix face of the fracture surface, and a sliver of the posterior right $I_{1}$ crypt wall adheres to this surface.

A nearly perfect natural midline section is seen through the posterior aspect of the symphysis on the right. The gnathion (GN) to ID axis makes an angle of $47^{\circ}$ with the alveolar margin defined from ID to $\mathrm{dM}_{1} / \mathrm{dM}_{2}$. The broken profile of the alveolar planum (planum alveolare) is smooth, but the area deep to the superior transverse torus displays a roughened surface which interlocked with the left symphysis. The right $I_{1}$ crypt is sectioned by symphyseal cleavage to reveal mesial, labial and lingual portions of the fully developed crown. The $I_{1}$ occupies a triangular crypt, the lingual crown face placed 1.8 anterior to the posterior crypt wall at mid-crown level. A poorly defined crypt floor defines inferiorly a hollowed area of approximately 4 diameter. This space occupies the base of the symphysis posteroinferior to the $I_{1}$ crown base. The superior third of the unerupted $I_{1}$ crown lies about 1 posterior to the terminal $\mathrm{dI}_{1}$ root. The crown and root are separated along the 6.0 overlap distance by matrix, the deciduous incisor root displaced anteriorly by matrix wedging.

D. Posterior aspect. The alveolar margin is nearly intact and shows three pairs of well defined gubernacular canals (canalaculigubernaculam) associated with the unerupted permanent anterior dentition. Members of the median canal pair are about 1.5 in diameter and situated behind the $\mathrm{d} \mathrm{I}_{1} / \mathrm{dI}_{2}$ position. The central pair members are oval in shape, measure 3.0 long and 1.5 wide on the left, and are located distolingual to $\mathrm{dI}_{2}$ on the alveolar margin. The circular posterior pair members measure about 1.0 in diameter and are sited lingual to the $\mathrm{d} \overline{\mathrm{C}}$ 's. The alveolar margin at the midline is missing. There appears to be a matrix filled guber nacular canal lingual to the right $d M_{1}$ and a smaller incipient one lingual to the left $\mathrm{dM}_{2}$.

The posterior symphyseal profile is best seen in cross section. Posterior to the alveolar margin is a long sloping alveolar planum, concave along both vertical and horizontal axes. Multiple microforamina perforate this surface, especially on the left The alveolar planum terminates in an incipient superior transverse torus which does not overhang the area of the genioglossal fossa (fossa genioglossi) in true occlusal view but represents a change in slope of the posterior symphyseal contour. The midline fracture surface across the planum is straight, but upen turning across the superior transverse torus, the surface becomes jagged with an interlocking effect. Matrix wedging has separated the adjacent corpora here by about 1.0. Across the incipient torus are fine, vertically oriented striae, and immediately to either side of the midline are microforamina. The poorly defined genioglossal fossa area is damaged. A median elevated ridge crosses the small inferior transverse torus (torus transwersus inferior) at the base of the corpus, probably representing the insertion of $\mathrm{m}$. geniohyoideus. Prior to breakage, this ridge probably constituted the left portion of the mental spines (spinae mentales). About 5 lateral to the midline at the level of the inferior transverse torus are paired microforamina, symmetric about the midline.

E. Medial aspect. A rounded alveolar promin ence (prominentia alveolaris) which merges smooth ly with the rounded lateral extent of the incipient superior transverse torus is preserved on both sides.

F. Basal aspect. The small portion of basal

\section{TABLE 2}

Selected mandibular measurements: L.H.-2

\begin{tabular}{|c|c|}
\hline -Bi-d $\overline{\mathbf{C}}$ internal alveolar margin minimum breadth $\ldots \ldots \ldots \ldots \ldots \ldots$ & $18 \pm 1$ \\
\hline - Minimum parallel breadth of corpus perpendicular to corpus axis at $\operatorname{RdM}_{2}$ & 16.7 \\
\hline mphyseal height (ID to GN) $\ldots \ldots \ldots \ldots \ldots \ldots \ldots \ldots$ & \\
\hline um symiphyseal breadth & \\
\hline -Dista & 16.6 \\
\hline -Distance distal RdC alveolus to distal Rd $\mathrm{M}_{2}$ alveolus . & . 19.8 \\
\hline
\end{tabular}


contour preserved below the right $\mathrm{dI}_{2}$ bears a small, indented weathered patch and no true digastric fossa (fossa digustrica). The basal contour displays little relief and turns posterosuperiorly toward the midline to merge with the inferior extent of the low mental spine. In contrast to the dental arch, the basal arch apparently had widely diverg ent arms and a shallow parabolic shape.

G. Occlusal aspect. The dental arcade displays exaggerated divergence due to the distortion detailed above. Only the deciduous incisor roots remain, these set in an evenly rounded arc. In true occlusal orientation the basal contour and dental arch superimpose at the $\mathrm{dM}_{2}$ level. There is no extramolar sulcus (sulcus extramolaris) lateral to $M_{1}$, the ramus appearing to arise at the alveolar level, very close to the alveolar margin. The pos teriormost symphyseal midline in occlusal aspect lies on the inferior transverse torus at midcrown $\mathrm{dM}_{2}$ level.

II. The dentition.

A. Deciduous dentition. 1. Deciduous central incisor. The crowns of right and left $\mathrm{dI}_{1}$ are miss ing. The roots are roughly circular in section, displaying an even distal taper. The mesiodistal and labiolingual root diameters at the alveolar margin are 3.5 and 3.7 respectively, and the distance from alveolar margin to distal root tip is $\mathbf{1 4 . 2}$ on the right.

2. Deciduous lateral incisor. These crowns are similarly damaged, leaving only roots. They are obscured distally but seem longer than the $\mathrm{dI}_{1}$ roots. The mesiodistal root diameter at the alveolar margin is 3.3 and the labiolingual diameter 4.7 on the left side.

3. Deciduous canine. Both $\mathrm{d} \bar{C}$ crowns are badly damaged and retain only small patches of enamel surface. Viewed occlusally the crown shape is a mesiodistally elongate ovoid. The right $\mathrm{d} \bar{C}$ retains a sharp, pointed dentine core whose apex is placed just mesiad of the crown center, 7.5 on a direct measure above the lingual enamel line location. As judged from this dentine core, the $d \bar{C}$ is asymmetric, with anterior cingulum more elevated than posterior. The posterior cingulum appears to have consisted of a distinct cus pule separated from the main cusp by distal labial and lingual grooves in the adhering enamel. The anterior cingulum is defined by a similar but weaker labial groove. Lingual morphology is largely obscured by damage, but a strong distal lingual ridge now defined only on the exposed dentine face connects major cusp apex with crown base. There was probably a mesial lingual groove. The root measures 4,9 mesiodistally and 5.7 labiolingually at the alveolar margin on the right, and about 16.0 from enamel line to distal tip on the left

4. Deciduous first molar. The tooth takes the occlusal shape of a parallelogram with particularly protuberant mesiobuccal corner. The five usual lower molar cusps are present on the right side the hypoconulid not defined on the left. The distolingual (entoconid) and distal (hypoconulid) cusps are very small. Wear has exposed dentine in small patches on the protoconid, metaconid and hypoconid apices. The largest and highest cusp is the protoconid. It presents a flattened, sloping buccal face above the swollen cervical region. This face bears a very weak depression on its mesial aspect. The enamel line reaches its most inferior extent below the protoconid.

The metaconid is set distolingually to the protoconid. It is roughly the same size as the hypoconid in occlusal extent but is nearly equivalent in height to the protoconid. These anterior cusps dominate the tooth in vertical extent. Lingual to the anterior protoconid ridge is a lingually facing anterior fovea whose continuity with the mesiolingual metaconid face is indeterminate. An incipient mesial accessory cusp lies mesiad of the protoconid, defined lingually by the buccal extent of the anterior fovea and bucally by the depression in the protoconid face.

The transverse crest connecting protoconid and metaconid is more elevated than that joining protoconid and hypoconid. The buccal crown face bears a deeply incised, anteroinferiorly directed buccal groove between protoconid and hypoconid which continues occlusally to cross the crest between these cusps. A deep, triradiate central fovea is located distad of the crown center. Major grooves dividing metaconid from entoconid, and hypoconid from hypoconulid originate here. The right $\mathrm{dM}_{1}$ preserves a distolingual corner of low elevation and small size which is divided into entoconid and hypoconulid. The left antimeric partner shows no such division and a hypoconulid is not de fined. There is a weak, distally placed lingual groove.

The tooth bears two widely divergent roots, best exposed on the left. The lengths of these roots from enamel line to tip are 10.2 (mesial) and 9.1 (distal). The buccal root tips are 9.7 apart

5. Deciduous second molar. The $\mathrm{dM}_{2}$ shape is an irregular ovoid, wider across its distal extent. Five major cusps are arranged in a Y-pattern with clear metaconid/hypoconid contact. The largest and highest cusp is the metaconid, followed in diminishing size order by the hypoconid, proto conid, hypoconulid, and entoconid. The buccal cusps are rounded and polished by wear, with a tiny patch of exposed dentine on the lingual protoconid face. The lingual cusps show polishing and remain sharp and elevated. Secondary fissuration is minor. The protoconid is set mesiad of the metaconid as is the hypoconid of the entoconid. There are two lingual grooves, a major posterior one between metaconid and entoconid, and a minor one in the lingual metaconid face. Two strong buccal grooves extend vertically to midcrown level on either side of the hypoconid. Their inferior termini are abrupt, but they are continuous across the occlusal rim with the grooves between protoconid, hypoconid, and hypoconulid which radiate from the central fovea.

A well developed anterior fovea is present, bounded by a sharp anterior rim bearing a lingual acces sory cusp. A second incipient fovea is superimposed upon the crest joining protoconid and metaconid. The fissure between entoconid and hypoconulid bifurcates distally to define an incipient tuberculum sextum. There appear to be two roots, placed mesially and distally below the crown and com. pressed in the same direction. Root divergence is estimated at slightly less than that of the $\mathrm{dM}_{1}$.

B. The permanent dentition. 1. Permanent central incisor. As displayed in the right symphysis. the unerupted $I_{1}$ crown shows little apparent re 
TABLE 3

Dental measurements : L.H.-2

\begin{tabular}{|c|c|c|c|c|c|c|c|c|c|c|}
\hline \multirow[b]{2}{*}{ Side } & \multicolumn{2}{|c|}{$\mathrm{d} \bar{C}$} & \multicolumn{2}{|c|}{$\mathrm{d} \mathbf{M}_{1}$} & \multicolumn{2}{|c|}{$\mathrm{d} \mathbf{M}_{\mathbf{2}}$} & \multicolumn{2}{|c|}{$I_{1}$} & \multicolumn{2}{|c|}{$M_{1}$} \\
\hline & $\mathbf{R}$ & $\mathbf{L}$ & $\mathbf{R}$ & $\mathbf{L}$ & $\mathbf{R}$ & $\mathbf{L}$ & A & $\mathbf{L}$ & $\mathbf{R}$ & $\mathbf{L}$ \\
\hline $\mathrm{M} / \mathrm{D}$ & 6.2 & $\mathrm{X}$ & 9.1 & 9.2 & 12.6 & 12.4 & $X$ & $\mathbf{X}$ & $(14.0)$ & (13.7) \\
\hline $\mathbf{B} / \mathbf{L}$ & $\mathbf{X}$ & $\mathrm{X}$ & $(7.6)$ & $\mathrm{X}$ & 10.6 & 10.6 & 7.7 & $\mathrm{X}$ & (13.9) & $\mathrm{X}$ \\
\hline $\mathrm{C} / \mathrm{I}$ & - & - & - & & & - & 13.5 & $\mathbf{X}$ & - & \\
\hline
\end{tabular}

lief. The gingival eminence is weak and featureless, continuous with the gently concave lingual crown surface. At least three small mamelons occupy the exposed incisal margin. There is an incisal ridge posterior to the sharp occlusal crown edge. Faint indications of a mesial lingual groove and marginal ridge are present. Weak perik ymata cover the crown surface. Root formation is in initial stages.

2. Permanent canine. The crown of the unerupted, incomplete permanent canine embedded in the broken left corpus presents a smooth labial face. The crown base is beveled, with no root formation. Fine perikymata occur as concentric rings around the crown base. The crown measures 11.7 from incomplete base to apex.

3. Permanent third premolar. The buccal face of the unerupted $P_{3}$ crown is exposed between the left $\mathrm{dM}_{1}$ roots. Strong mesial and distal buccal grooves are visible.

4. Permanent first molar. Both first molars are damaged, the left having lost part of the crown. Overall crown shape is square, with rounded mesial corners and distal face. Mild erosion on the right molar precludes determination of occlusal status, but the mesial edge of the left protoconid bears a mirrorlike occlusal facet from contact with the upper dentition. The basic five cusps are present, with clear metaconid/hypoconid contact in the Y-fissure pattern. Secondary fissuration is well developed, giving the occlusal crown surface a crenulate appearance. Protoconid and metaconid are the largest cusps, slightly larger occlusally and more elevated then the remaining three cusps. There is a strong anterior fovea. There is one weak lingual groove between metaconid and entoconid, and two well marked buccal grooves, the mesial one deeper and ending abruptly in a fovea at midcrown level. A slightly elevated vertical ridge 1.5 in length represents a protostylid on the mesiobuccal protoconid face. The fissure between entoconid and hypoconulid terminates distally in a small transverse pit representing the posterior fovea. Barely visible perikymata are present just above the enamel line. The line projects weakly in. feriorly at the mesial/distal root division level. Mesiodistally compressed mesial and distal roots are not fully formed.

LAETOLIL HOMINID 3: Locality 7 (plate 2 A-D table 4)

Specimen consists of: Isolated teeth: (a): $\operatorname{Rd} \mathbf{M}^{2}$,

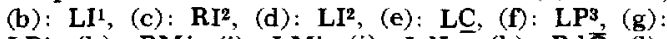
$\mathbf{L P}^{4}$, (h): RM ${ }^{\mathbf{1}}$, (i): $\mathbf{L M}^{1}$, (j): $\operatorname{LdI}^{-},(\mathbf{k}): \operatorname{RdC},(\mathbf{l})$ : $\mathbf{R d M}_{1},(\mathbf{m}): \mathrm{I}^{-},(\mathbf{n}): \mathbf{R C},(\mathbf{o}): \mathbf{L C},(\mathbf{p}): \mathbf{R P}_{3},(\mathbf{q}):$ $\mathbf{R P}_{4},(\mathbf{r}): \mathbf{L P}_{\mathbf{4}},(\mathrm{s}): \mathbf{R M}_{\mathbf{1}},(\mathrm{t}): \mathbf{L M}_{\mathbf{1}}$.

Preservation: Hominids 3 and 6 represent at least two individuals of similar dental age. These individuals consist of teeth derived in mixed state from a very small patch of sediment. The lower right premolars were physically as sociated. held together by matrix in proper anatomical position. The remaining teeth present difficulty in association due to their isolate, fragmentary and unerupted conditions.

All antimeric associations were made and interproximal contact facets of erupted teeth were used to establish identity. Two maxillary dentitions were identified by non-antimere canines and incisors as well as duplicate $\mathrm{Rd}^{2}$ and $\mathrm{RM}^{1}$. Incisors and canines were assigned to hominids 3 or 6 on the basis of size and lingual relief, greater in L.H.-3 as associated. Support for the morphological association is afforded by details of color and preservation as well as the observation that L.H.-6 as associated presents a continuous tooth row $I^{2}$ to $M^{1}$.

There is no duplicity in the mandibular teeth. $P_{4}$ and $M_{1}$ are represented as antimeric pairs, and $\mathbf{P}_{3}$ was associated with $\mathbf{P}_{4}$. While it probably never will be proven, there is at present no reason to believe that the other mandibular teeth belong to a different individual. Association of all mandibular teeth as representing one individual seems the most likely on the basis of available morphological and preservational evidence. The problem of associating mandibular and maxillary dentitions was approached through microscopic examination of the relevant first molar occlusal surfaces. The mandibular dentition was found to best match L.H. -3 and thus final association was made. Two elements of the original mixed sample retain intermediate status. These are a fragmentary right $\mathrm{d} C$ and left $d M^{1}$. Since there are no left side elements attributed to L.H.-6 and the L.H.-6 $P^{3}$ displays clear root formation, it appears less likely that the deciduous molar belongs to this individual. Becau se this sort of association remains more tenuous than that detailed above, both the $\mathrm{dC}$ and $\mathrm{dM}^{1}$ are described independently as $L . H$. " $3 / 6$ ", with the stated possibility that they belong to either individual.

The teeth display breakage and mechanical abrasion but enamel surfaces show excellent detail where preserved. The $\mathrm{dM}^{2}, \mathrm{C}$, and $\mathrm{P}_{4}$ crowns have cracks, but total distortion is minimal. The right $\mathrm{dM}^{2}$ and $\mathrm{M}^{1}$ roots are affixed to small patches of adhering maxillary bone.

Morphology:

I. The dentition.

A. The upper deciduous dentition. 1. Deciduous second molar: L.H.-3(a). The crown shape is quadrangular, with rounded lingual apex and protuberant mesiolingual angle. Four major cusps 
are arranged from largest to smallest in occlusal extent as mesiolingual (protocone), mesiobuccal (paracone), distobuccal (metacone) and distolingual (hypocone). There is extensive wear on the lingual cusps, with a $3.9 \times 2$ depressed dentine exposure on the protocone and a much smaller patch on the hypocone. The buccal cusps are polished and retain fairly sharp, elevated apices. Buccolingually elongate interproximal facets for $\mathrm{dM}^{1}$ and $\mathrm{M}^{1}$ are placed on mesial and distal crown faces. Wear striae are directed mesiolingually across the enamel surface of the protocone.

The lingual protocone edge is rounded and bulging. A weak groove extends halfway down the sloping lingual face between protocone and hypocone. A groove of similar dimension crosses the steeper buccal face, separates paracone and metacone and ends in a marked pit at midcrown level. The latter groove occupies the center of a U shaped depression defined by slightly elevated buccal ridges descending from paracone and metacone apices and converging inferiorly toward the pit. A parastyle composed of a weak groove and ridge occupies the mesiobuccal paracone corner. The buccal groove joins the occlusal fissure dividing paracone and metacone. The lingual groove is set apart from one lingual arm of the posterior fovea by a low crest joining protocone and hypocone. Two weak grooves on the worn lingual face of the protocone may represent a Carabelli feature. There is a strong oblique crest and a simple central fovea. The anterior fovea is a deep, buccolingually directed groove placed slightly buccal to the tooth midline and terminating in a $90^{\circ}$ turn in the mesial paracone face. The posterior fovea is triradiate, centrally placed, and confined by the oblique crest. Secondary fissuration is largely obscured by wear except as moderately developed between paracone and metacone.

Two mesiodistally compressed roots lie below the major buccal cusps and a larger, more divergent root is placed below the posterior protocone. The buccal roots are slightly damaged but are about equal in length, estimated at 12 below the enamel line. The lingual root is broken.

B. The upper permanent dentition. 1. Permanent central incisor: L.H.-3(b). The unerupted $I^{1}$ shows a damaged, incompletely developed root. The crown is intact, presenting convex labial and concave lingual faces. The crown edges and incisal margin are straight. The mesial incisal angle is sharp, the distal more evenly rounded. The labial face displays a surface roughened by weak, irregular vertical furrows and distinct horizontal concentric perikymata. Weak marginal ridges and associated grooves occupy the edges of the labial face. Mesial and distal crown faces bear slight central grooves running from incisal margin to enamel line in the former and to midcrown level in the latter. Mesial and distal areas of the incisal margin are slightly elevated. A single centrally placed mamelon interrupts the sharp incisal edge. A marked incisal ridge lies about 1 lingual and inferior to this edge. Mesial and distal marginal ridges are strong but a smooth transition with the lingual fossa diminishes their prominence. The gingival eminence bears a major distal tubercle connected to the lingual crown face by a strong vertical crest. Mesial to the crest and tubercle a deep midline cleft weakens and disappears in the lingual fossa and ends basally in a deep, narrow pit on the incisal portion of the gingival eminence. The mesial extent of the central cleft is defined by a second lingual ridge continuous with a basal lingual tubercle, smaller than the distal tubercle but located on the same level of the gingival eminence.

2. Permanent lateral incisor: L.H.-3(c,d). The intact, unerupted left $I^{2}$ crown is much smaller than that of the $I^{1}$. Root development is not as complete, but the crown is fully developed, presenting convex labial and concave lingual faces. Unlike $I^{1}$, the incisal margin slopes markedly with respect to the vertical crown axis, resulting in a mesial angle of nearly $90^{\circ}$ and lack of a true distal incisal angle. The Iatter is seen only as an evenly rounded transition from incisal to distal crown edges. The labial face is strongly conxev, bearing concentric, weakly indented lines 8.6 and 10.3 below the incisal edge that probably represent minor hypoplastic episodes. Labial marginal ridges are incipiently developed. Mesial and distal crown faces are evenly convex and bulging. Three distinct mamelons occupy the sharp incisal edge and a weak lingual incisal ridge passes parallel to this sloping edge. The lingual fossa is deeply hol lowed between mesial and distal marginal ridges which surmount the gingival eminence. This eminence bears a single strong lingual tubercle which joins a weak raised ridge just distad of the crown center to divide the lingual fossa cervically.

3. Permanent canine: L.H.-3(e). The beveled basal edge of this unerupted tooth indicates incomplete crown development. Nearly the entire basal edge is damaged and no root is preserved even if formation had begun. The distal crown apex and mesial crown edge are damaged. Crown shape in labial aspect is a vertically elongate diamond with truncated base. This effect derives from straight, symmetric mesial and distal occlusal edges combined with constriction of the cervical portion. The labial face shows incipient mesial and distal grooves demarcating the crown shoulders. Weak indented horizontal lines 9.2 and 12.8 below the apex encircle the labial face and probably indicate mild hypoplastic episodes. The mesial crown shoulder appears stronger than the distal. The lingual face bears much relief The gingival eminence is damaged in part, its occlusal ex tent bearing a complex of sharpened ridges and crenulations which pass onto the distolingual crown face. Major ridges continuous with mesial and distal edges of the eminence form lingual por tions of anterior and posterior cingula. Mesiad of the crown midline a strong, straight vertical ridge reaches from anterior gingival eminence to crown apex. The groove and fossa between this ridge and the mesial crown shoulder are well marked. A similar but wider distolingual fovea lies between the gingival eminence and distal cingular ridge

4. Permanent third premolar: L.H.-3(f). The unerupted crown shows apparently complete enamel development but no root formation. Viewed occlusally, crown shape is oval, with idented mesial and convex distal faces. There are major buccal and lingual cusps, the latter placed mesiad of the buccolingual crown axis. The lingual crown face 
is slightly more sloping than the buccal and bears a smooth surface with a minor mesiolingual groove. The buccal face bears two vertical grooves, a larger mesial and smaller, higher distal groove. The buccal cusp apex is sharper and roughly 1 higher than the lingual. Primary fissuration is $\mathrm{H}$ shaped, with poorly developed mesiolingual and distobuccal arms. There are small anterior and posterior foveae. The anterior fovea radiates a small groove which passes across the occlusal mar gin onto the mesial crown face. Secondary fis suration is moderately developed, most marked distally. The crown base displays fine concentric perikymata.

5. Permanent fourth premolar: L.H.-3(g). Crown development of this unerupted tooth is at rough ly the same stage as $P^{3}$. Only the lingual cusp and lingual face of the buccal cusp remain, and much of the crown base is missing. The $\mathrm{P}^{4}$ is slightly larger than the $\mathrm{P}^{3}$, with slightly greater mesiolingual groove development. Cusp placement and primary fissuration are also similar. The distobuccal arm of the pattern is fully developed, with more elongate and deeper incision of anterior and posterior foveae. Secondary fissuration is more pronounced, and an incipient cusplet occupies the lingual talon edge. Strong perikymata are present, particularly around the distal crown. Unworn enamel thickness at the broken buccal cusp is 1.4 .

6. Permanent first molar: L.H.-3 (h,i). The right crown is intact, the left represented by a lingual crown fragment with lingual groove. Occlusal crown shape is that of a truncated wedge. The widest part of the crown is lingual, opposite the $\mathrm{dM}^{2}$ condition. The protocone shows greatest wear, with rounded cusp apex and large occlusal facet along its mesiolingual face. Microscopic wear striae cross this facet from mesiolingual to distobuccal. Paracone and hypocone show mirrorlike occlusal facets sloping toward the mesiodistal crown axis and the metacone bears a similar basal facet. An interproximal facet for the $\mathrm{dM}^{2}$ occupies the mesial crown face. The buccal slope is slightly steeper than the lingual. There are four major cusps: a large protocone, smaller and equal sized paracone and metacone, and a small hypocone. In unworn condition both buccal cusps probably reached a higher elevation than the lingual cusps. There are single major buccal and lingual grooves, the former occupying a depres. sion as in the $\mathrm{dM}^{2}$. The mesiobuccal paracone corner displays a small bifurcate groove near the cusp apex, and the lingual protocone face bears a weak vertical groove nearly reaching the enamel line. A deep pit on the mesiolingual protocone face represents expression of the Carabelli trait. The oblique crest is weak, composed of a small tubercle joining protocone and metacone. Mesiad of this crest the buccal radiation of the central fovea joins the buccal groove. The posterior fovea is triradiate, with buccal and lingual arms defining an incipient hypoconule. The mesiolingual posterior fovea arm is continuous with the lingual groove. A small pit lies between protocone and paracone, and a strong isolate anterior fovea is defined by a weak crest joining these cusps.

The three major roots are incompletely developed. The two buccal roots are mesiodistally compressed and placed below paracone and meta cone. The larger lingual root is buccolingually compressed and set beneath the lingual crown center.

C. The lower deciduous dentition. 1. Deciduous incisor: $\mathbf{L}, \mathrm{H},-3(\mathrm{j})$. This broken crown probably represents a left $\mathrm{dI}_{2}$ due to distal root angulation, but only distal halves of labial and lingual crown faces remain, the distal crown edge and mesia crown half broken away. The incisal edge bears a 0.5 -wide strip of exposed dentine. Neither crown face as preserved displays much relief. The labial face is smooth and gently convex with a nearly imperceptible enamel line. The lingual face is gently concave with a swollen gingival eminence. The root is mesiodistally compressed, with strong mesial and distal grooves. Its estimated length below the lingual enamel line prior to apex breakage is 14

2. Deciduous canine: L.H.-3(k). The entire mesiolingual crown is missing. Most of the labial dentine core is preserved, and a small enamel flake bearing the distal labial groove separates major cusp from posterior cingulum. This cingulum ap pears strong while the major cusp is tall and conical. The root is mesiodistally compressed with a strong mesial groove. It measures about 17 from root tip to labial enamel line position.

3. Deciduous first molar: L.H.-3(1). The crown suffers enamel loss on mesiolingual and distal edges. It is widest across hypoconid and entoconid. The hypoconid is heavily worn with exposure of a 2.3-diameter dentine island. Smaller dentine exposures occur on protoconid and metaconid apices. The protoconid is occlusally dominant, followed in size by metaconid and hypoconid, and finally by entoconid and hypoconulid. The buccal protoconid face presents a long, flat sloping surface bearing microscopic wear striae with primary vertical orientation. The enamel line projects furthest beneath the protoconid. The hypoconid, entoconid, and hypoconulid are worn, but were placed at a much lower unworn elevation than protoconid or metaconid. The lingual crown face is steeper than the buccal and bears a weak groove between metaconid and entoconid. A still smaller groove lies on the lingual side of the metaconid and is truncated by the enamel fracture. A single buccal groove is placed between protoconid and hypoconid, obliquely continuous with the occlusal fissure between these cusps. An incipient groove occupies the superior protoconid face. Remaining primary fissuration reveals strong separation of metaconid and entoconid. A deep anterior fovea lies mesiolingual to the strong transverse crest joining protoconid and metaconid. The fovea is deeply incised in the lingual protoconid face. A weak crest obscured by wear joins protoconid to hypoconid. The two thin roots are convergent apically, partially resorbed, mesiodistally compressed, incipiently bilobed, and placed under mesial and distal crown halves.

D. The lower permanent dentition. 1. Permanent lower incisor: L.H.-3(m). The broken halfcrown of a lower incisor is preserved. Its identity cannot presently be established, but the rounded distal incisal angle suggests that the fragment represents right $I_{1}$ or $I_{2}$. The labial crown face is smooth and convex, the lingual face equally con- 
cave, The tooth appears unerupted and proximal root fragments are embedded in matrix at the crown base. The incisal edge is sharp. There is a weak incisal ridge, and a featureless, swollen gingival eminence. A slight vertical groove crosses the incisal half of the lingual crown face. Very fine concentric perikymata are present labially.

2. Permanent canine: L.H.-3(n,o). The unerupted, almost fully developed right canine crown is intact, but only the distobuccal face of the left remains. The crown base is sharply beveled with a trace of root development. In labial aspect the crown is asymmetric, with apex situated slightly mesiad of the crown midline, the anterior cingulum expressed to a point greater than half the crown height, and posterior cingulum occupying about a quarter of the total crown height. The superomesial occlusal edge is consequently angled forward from the apex at about $50^{\circ}$ to the base while the distal profile is longer and slightly steeper.

The labial face is gently convex from apex to enamel line and more strongly convex mesiodistally. A slightly indented pair of lines thought to represent a hypoplastic episode is located 8.6 below the crown apex and is present bilaterally. There are strong mesial and distal labial grooves, the latter nearly reaching the apex and the former reaching the top of the anterior cingulum. The distal labial groove bifurcates 3 above the present crown base to circumscribe a distinct distal cusp. Marked mesial and distal lingual grooves are separated by an extremely prominent, sharp central lingual ridge set strongly distad of the crown center. The distal lingual groove is $V$-shaped, very narrow and deeply incised. It extends from its basal fovea mesiad of the posterior cingulum to a small pit at the crown apex. The basal aspect of the central lingual ridge is slightly depressed, its distal margin bearing convoluted roughenings. The gingival eminence is incompletely formed, represented by a slight basal swelling.

3. Permanent third premolar: L.H.-3(p). The $P_{3}$ crown, fully formed but unerupted with root traces, is ovoid in occlusal aspect, elongate along a mesiobuccal to distolingual axis and narrowest distolingually. Placement of larger buccal and smaller lingual cusps is asymmetric with respect to the longitudinal tooth axis, the lingual cusp mesiad of the axis. The buccal cusp is large in occlusal area and roughly $l$ higher than the lingual cusp relative to the crown base. Mesial and distal occlusal ridges occupy the full crown length. Mesial and distal buccal ridges and associated grooves mark the edges of the wide buccal crown face. The mesial buccal groove ends in a pit 3.2 above the crown base while the distal diminishes gradually toward the base. There is a low posterior fovea and talonid. The walls of the talonid basin are radially crenulate, the fovea within bearing a strong mesiobuccal arm extending to a point immediately lingual of the buccal cusp apex. A transverse crest between major cusp apices is partially breached by the distal arm of a deep anterior fovea. The lingual cusp is small and conical, set apart from the strong lingual portion of the talon by a weak groove.

4. Permanent fourth premolar: L.H.-3(q,r). Both $\mathrm{P}_{4}$ crowns are present, the left better preserved and the right slightly expanded by a buccolingually directed crack. Both crowns are fully developed but unerupted, the right displaying broken traces of root formation. The crown is more symmetric than that of $P_{3}$, but similar in the larger buccal cusp and more protuberant distolingual angle. The major buccal cusp apex is roughly 0.5 higher than the lingual cusp apex relative to the crown base. The buccal crown face is broader, more convex and less steeply sloping than the lingual, bearing a weak groove on its mesial corner. Weak lingual and stronger buccal central grooves reach the midcrown level before vanishing. These are continuous with arms of the distal fovea which distinguish major from minor buccal and lingual cusp pairs. The talonid is composed of small buccal and lingual cusps placed on distobuccal and distolingual crown corners and joined by a small posteroconvex crest. The distolingually placed posterior fovea is wide and deep, its walls heav ily crenulated by radial secondary fissuration. It joins the smaller, more buccally placed anterior fovea through a small notch incised in the weak ridge between major buccal and lingual cusps. The anterior fovea is incipiently divided into mesial and distal components by a discontinuous ridge.

5. Permanent first molar: L.H.-3(s,t). The right $M_{1}$ is represented by mesial and buccal crown faces, protoconid, and portions of metaconid and hypoconid. The left crown is complete, with intact root system. The occlusal shape of the crown is a rounded square, the distal face more rounded than the mesial and the buccal more sloping than the lingual. Wear has rounded the protoconid and produced polished, flat occlusal facets near the other cusp apices. A concave, rectangular in terproximal facet for the $\mathrm{dM}_{2}$ is placed on the occlusal half of the mesial crown face.

The five major cusps are arranged in a Y. pattern with metaconid/hypoconid contact. The metaconid is the largest and highest cusp, the protoconid smaller and the other three major cusps of smaller but equivalent size. A single lingual groove extending halfway down the lingual crown face is continuous with the occlusal fissure between metaconid and entoconid. A deep buccal cleft be tween protoconid and hypoconid extends from a deep fovea just above the midcrown level across the occlusal rim to join the primary fissure pat tern. The mesiobuccal corner of the protoconid bears a deep irregular groove about 1.5 in vertical extent. A smaller groove, similarly oriented but about 1.0 distal to the mesiobuccal groove defines a small protostylid on the buccal protoconid face. The right tooth displays similar effect but the distal groove is absent. A second major buccal groove situated on the distobuccal crown corner divides hypoconid and hypoconulid. Primary fissuration is strong. The division between protoconid and metaconid bifurcates anteriorly to form a buccolingually elongate anterior fovea whose lingual arm nearly reaches the metaconid apex. The hypoconulid is large and triangular, placed central ly on the distal crown. Secondary fissuration is moderate in degree. The enamel line bears sharp inferior projections at midcrown level above mesial and distal root divisions. Two major incompletely developed roots are placed mesially and distally. These are bilobed in section, with a major lobe under each major cusp except hypoconulid. The mesial root is nearly vertical. The distal root diverges distally, its buccal extension giving the 
TABLE 4

Dental measurements : L.H.-3

\begin{tabular}{|c|c|c|c|c|c|c|c|c|}
\hline \multirow[t]{2}{*}{ Deciduous } & \multicolumn{2}{|c|}{$\mathrm{dM}^{2}$} & \multicolumn{2}{|c|}{$\mathrm{d} \mathbf{I}-$} & \multicolumn{2}{|c|}{$\mathrm{d} \overline{\mathrm{C}}$} & \multicolumn{2}{|c|}{$\mathrm{d} \mathbf{M}_{1}$} \\
\hline & $\mathbf{R}$ & $\mathbf{L}$ & $\mathbf{R}$ & $\mathbf{L}$ & $\mathbf{R}$ & $\mathbf{L}$ & $\mathrm{R}$ & $\mathbf{L}$ \\
\hline $\mathrm{M} / \mathrm{D}$ & $\begin{array}{c}10.6 \\
(10.8)\end{array}$ & - & - & $\mathrm{X}$ & $\mathbf{X}$ & - & $(9.6)$ & - \\
\hline $\begin{array}{l}\mathrm{B} / \mathrm{L} \\
\mathrm{C} / \mathrm{I}\end{array}$ & $(12.6)$ & - & - & $\stackrel{5.0}{X}$ & $\begin{array}{l}\mathbf{X} \\
\mathbf{X}\end{array}$ & - & $(8.4)$ & - \\
\hline
\end{tabular}

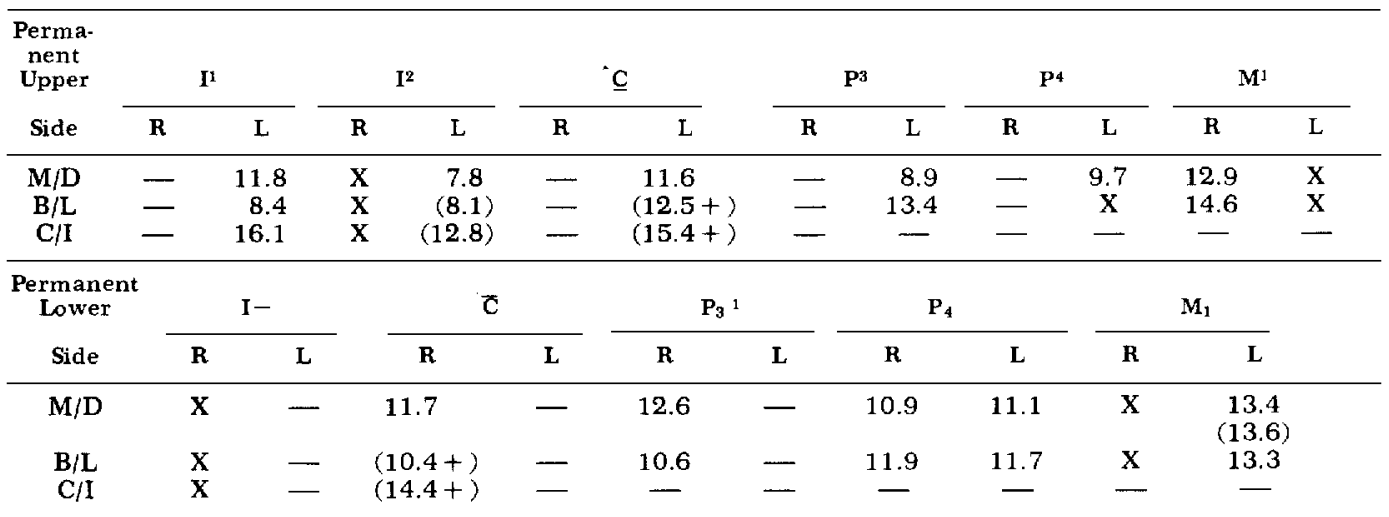

$1 \mathrm{P}_{3}$ profile difficult to accommodate in measurement scheme used. Maximum long axis $=13.3, \mathrm{minimum}$ short axis $=9.6$

root a twisted aspect. Fine perikymata encircle the crown.

LAETOLIL HOMINID 3/6: Locality 7 (plate 2E, table 5)

Specimen consists of: Isolated teeth: (a): RdC (b) : $\operatorname{LdM}^{1}$.

Preservation: Association with L.H.-3 or L.H.-6 cannot be established: see L.H.-3.

Morphology:

A. The deciduous upper dentition. 1. Deciduous canine: L.H.-3/6(a). Much labial enamel is missing from the dentine core. The crown is asymmetric, its shape altered by wear. A large occlusal patch of slightly cupped dentine is exposed on the distolingual portion of the main cusp. This patch measures about 2 in diameter, tapering rapidly to a point in the posterior cingular region. Weak labial and lingual grooves define the posterior cingulum. The anterior cingulum appears well developed but only the dentine core remains and reaches a slightly higher elevation than the distal cingulum. A worn, polished lingual ridge is placed slightly mesiad of the crown center. The gingival eminence is large and bulbous, bearing a small dentine exposure on its distal edge. The root is oval in section and labiolingually compressed, measuring $4.6 \times 5.3$ at the enamel line. Its distal half is missing.

2. Deciduous first molar: L.H.-3/6(b). This damaged specimen has lost enamel from mesiolingual and distolingual quadrants. It is wedge shaped in occlusal form, widest across the buccal cusps with a rounded apex protruding mesiolingually. Wear has produced a $2.3 \times 3.8$ dentine exposure on the protocone and a smaller patch on the hypocone. Tiny patches are also visible on the sharper paracone and metacone apices.
Curved and flattened partial interproximal contact facets for the $d \underline{C}$ and $d M^{2}$ are present.

There are two weak buccal grooves, the anterior deeper but neither reaching the enamel line. A 2.3-long, round raised ridge of enamel passes vertically across the buccal paracone face. The enamel line beneath the paracone extends a greater distance below the occlusal rim than that below the metacone. Most lingual enamel surface is damaged. Primary fissuration is largely obscured by wear, but the protocone was clearly the dominant cusp in occlusal size, flanked by a weak hypocone. A strong mesiobuccal accessory cusp is divided from the paracone by a deep transverse fissure. There appears to have been an oblique crest joining protocone and metacone. An elongate posterior fovea is present, its buccal aspect preserved as a deep furrow distal to the metacone.

There are one lingual and two buccal roots. The latter are slightly divergent, mesiodistally compressed, angled mesially, and set below paracone and metacone. The single lingual root is sited at midcrown level, its broken stump indicative of great divergence as it angles away from the crown in a direction nearly parallel to that of the worn occlusal surface.

LAETOLIL HOMINID 4: Locality 7. (Plates 3A-D, 4A-E; tables 6, 7)

Specimen consists of: Mandibular corpus with broken $R \bar{C}, M_{1}, M_{2}$; intact $R+L P_{4} ; \quad \mathbf{R P}_{3}, M_{3}$; $\mathrm{LM}_{1}, \mathrm{M}_{2}$.

Preservation:

I. The mandible. Small portions of fragile alveolar bone adjacent to canine and incisor sockets are damaged and the alveolar portion lateral to right $P_{3}$ to $M_{1}$ is slightly weathered. The left cor- 
TABLE 5

Dental measurements: L.H.-3/6

\begin{tabular}{cccccc} 
& \multicolumn{2}{c}{$\mathrm{d} \underline{\mathrm{C}}$} & & \multicolumn{2}{c}{$\mathrm{dM}^{\mathbf{2}}$} \\
\cline { 2 - 4 } \cline { 5 - 6 } Side & $\mathbf{R}$ & $\mathrm{L}$ & & $\mathbf{R}$ & $\mathrm{L}$ \\
\hline $\mathrm{M} / \mathrm{D}$ & $(6.8)$ & - & & - & 9.1 \\
$\mathrm{~B} / \mathrm{L}$ & $(5.3)$ & - & & - & $(9.4)$ \\
$\mathrm{C} / \mathrm{I}$ & $\mathrm{X}$ & - & - & - \\
\hline
\end{tabular}

pus is fractured obliquely through the mesial $\mathrm{M}_{3}$ root socket, the lateral alveolar margin reaching the distal $\mathrm{M}_{2}$ level and the basal contour reaching the mesial $\mathrm{M}_{3}$ level. The right corpus retains medial alveolar margin as far posterior as distal $M_{3}$, but here the fracture axis is oblique to the corpus in an anteroinferior direction, resulting in loss of basal contour posterior to the $M_{1}$ level. Only the anteroinferior roots of the rami are preserved. The nature of the fractured right corpus is indicative of prefossilization damage.

The specimen was recovered in two halves, fractured approximately at the midline. Slight warping of bone near the center of the broken right symphyseal surface prevents perfect joining of right and left corpora. The warped bone acts as a fulcrum, and when the posterior broken surfaces align properly, a gap across the anterior symphysis of approximately 0.75 remains. The corpora were joined primarily through reference to the surfaces across the posterior symphysis. The effect is thus one of decreasing bimolar breadth at $\mathrm{M}_{2}$ by between 0.5 and 1.0 from the true anatomical measurement, a relatively insignificant amount subsequently disregarded.

II. The dentition. The crowns of left $P_{4}$ and $M_{1}$, and right $\bar{C}, M_{1}$ and $M_{2}$ have been subjected to partial breakage and enamel loss. Only broken roots of the left $\bar{C}$ and $P_{3}$ remain. Portions of the empty alveoli of right and left $I_{1}$, and left $I_{2}$ and $M_{3}$ remain. The tooth enamel has undergone mild chemical weathering, particularly apparent on the occlusal surface of $\mathrm{LM}_{2}$ and the crown face of $\mathrm{RM}_{3}$.

Morphology:

I. The mandible.

A. Lateral aspect. In true lateral view, occlusal and alveolar margins converge posteriorly. Occlusal rim to alveolar margin measurements are $7.7,6.8$ and 5.3 lateral to left $P_{4}, M_{1}$ and $M_{2}$ respectively. As quantified in table 6 , the alveolar margin and basal contour also show strong posterior convergence. The alveolar margin is sharp lateral to $P_{4}$ to $M_{2}$. Its superior edge is placed an average of 1.0 lateral to the buccal edge of the tooth roots, and the alveoli consequently appear slightly too large for the roots they contain. The sharpened alveolar margin begins to deteriorate at $P_{4} / M_{1}$ level on the better-preserved left side and is rounded and vascularized lateral to $P_{3} / P_{4}$

The anterior ramus as represented by the lateral prominence (prominentia lateralis) and oblique line (linea obliqua) is preserved on the left corpus lateral to $\mathrm{M}_{2}$. This ramus root is placed high on the corpus, the lateral extent of the oblique line measuring about 25 above the base at the $M_{2}$ level.
The anteriormost extramolar sulcus lies superior to the oblique line and lateral to the alveolar margin at $M_{2}$. It loses distinction at the $M_{1} / M_{2}$ level as the oblique line fades anteroinferiorly. The area directly inferior to the oblique line presents a flat, featureless lateral aspect with no trace of lateral prominence below midcorpus level.

The alveolar portion is slightly swollen across the mesial $M_{1}$ root and slightly depressed lateral to $P_{4}$. A stronger anterior swelling reaches the midcorpus level and represents the $P_{3}$ jugum. This bulge is fairly continuous with the canine jugum anteriorly, and together these constitute the smooth but distinct transition from lateral to anterior corpus. A single mental foramen (foramen mentale) is centered 20.7 below the alveolar margin at the $\mathrm{P}_{3} / \mathrm{P}_{4}$ level of the left corpus. Its inferior border is sharp. The foramen opens superolaterally with a secondary narrow bony groove in its superior margin. The right corpus displays a similar foramen centered 21.1 below the alveolar margin at an equivalent position. Its inferior margin is also sharp, but it is directed more posteriorly than that on the left. There is no groove in its roof, but a minor accessory foramen communicates with the roof of the major foramen through an equivalent canal. Both right and left mental foramina are oval in shape, their long axes running anterosuperior to posteroinferior and measuring 3.6 in length. A bony groove probably representing partial reflection of the mental nerve and artery passes superiorly and slightly anteriorly from the accessory foramen on the right. Two smaller grooves passing anterior and superior to this accessory foramen are absent from the left side and thought to be postmortem defects instead of real anatomy.

The mental foramina are centered just an teriorly to the inferior extensions of oval hollowed areas, roughly $17 \mathrm{long}$ and 13 high. These gentle depressions are superiorly, anteriorly and posteriorly bounded by the alveolar margin, $P_{3}$ and $M_{1}$ jugae respectively. The depressed area is slightly smaller but deeper on the right corpus, reaching an overall depth of 1.5 . It is bounded inferiorly on both sides by a poorly defined lateral superior torus (torus lateralis superior) which is surmounted at its point of greatest prominence by the mental foramen. The torus merges with the distal $\overline{\mathrm{C}} / \mathrm{P}_{3}$ bulge anteriorly while losing definition as it approaches the flat corpus posteriorly to disappear entirely below the $M_{1}$ position. It passes roughly parallel to the base, 15 on a direct measure above the basal contour at $\mathrm{P}_{\mathbf{4}} / \mathrm{M}_{1}$

Immediately below the torus, passing longitudinally from a point inferior to the $\overline{\mathrm{C}} / \mathrm{P}_{3}$ bulge to a point below the distal $\mathrm{M}_{1}$ position is a weak intertoral sulcus (sulcus intertoralis). The left side displays a roughened surface inferior to the sulcus representing a weak marginal torus (torus marginalis). The anterior portion of this roughening takes the form of two or three low ridges oriented anterosuperior to posteroinferior at roughly $35^{\circ}$ to the basal contour. These represent very poorly developed platysmatic striae (striae platysmatica). The marginal torus is largely defined by the intertoral sulcus above, and termin ates anteriorly in a basally oriented anterior marginal tubercle (tuberculum marginale anterius). Split-line effect due to natural weather- 
ing crosses the bony cortex following longitudinal alveolar, basal, and ramus root contours. There is a strong Curve of Spee whose radius is roughly 125 . The wear plane defines a twisted "helicoidal" pathway, buccal wear most intense at the $\mathrm{M}_{1} / \mathrm{M}_{2}$ level.

B. Anterior aspect. The outstanding feature of this aspect is the pathological reaction largely confined to the right alveolar portion. The area involved lies between midline and canine jugum, affecting medial and buccal aspects of the latter. The distal tip of the right $I_{1}$ socket is preserved, but no trace of right $I_{2}$ socket remains and premortem tooth loss is likely. Alveolar resorption involves the medial left $I_{1}$ socket wall, exposing much of the anterior and lateral faces of the right $\bar{C}$ root. The reaction is not entirely resorptive as the $I_{2}$ socket position is now obliterated by a filling of irregular, coarse spongy bone. A roughened, hollowed effect characterizes the right superior anterior aspect. The alveolar region here is composed largely of pitted, spongy reactive bone.

The left alveolar portion is more intact and displays only minor resorptive effects. The distal left $I_{2}$ socket reaches a level about 3 inferior to that of the $I_{1}$ socket and about 26 above the basal contour. The canine roots occupy large alveoli terminating approximately at midcorpus level. Much alveolar portion is missing, and while it is difficult to ascertain the degree of alveolar prognathism or that of an incurvatio anterior to the incisor sockets (incurvatio mandibulae), it is unlikely that either effect was great. The anterior aspect is remarkable for its lack of relief. It presents a swollen or bulbous median profile whose maximum anterior extent is at midcorpus. This rounded eminence does not satisfy the definitions of either a mentum osseum or tuber symphyseos because it is not clearly separated from the alveolar portion by an incurvatio and does not occupy a basal position. The anterior symphyseal profile slopes sharply posteriorly below the rounded median eminence. A narrow and deep (2.9 in vertical extent) basal incisura (incisura submentalis) lies between marked basal ridges of the anterior marginal tubercles. Weathering induced split-lines converge on the midline base of the rounded eminence from all directions except basally.

C. Symphyseal aspect. Prior to joining of right and left corpora, details of internal symphyseal anatomy were visible. The broken left symphyseal surface reveals midline only in superior extent, the fracture trending inferiorly and slightly to the left of the midline. Clear definition of cortical and medullary portions is not pre. served. Anterior to the genioglossal fossa position is a $7 \times 10$ area of open cancellous bone. The midline anterior to this vertically oriented area displays a cortex of 3.4 thickness. The cortex clearly thickens basally. Cortical bone texture is lamellar and arranged in concentric rings following the contour of the basal symphyseal section. Break. age is oblique and measurements therefore of limited value. Basal and inferior transverse toral cortices show bone thicknesses roughly twice that of the anterior symphysis.

The broken surface of the right posterior symphysis crosses the alveolar planum and superior transverse torus, passing obliquely to the left of the midline in the area of the inferior transverse torus and genioglossal fossa. In superior extent, the break is a fair approximation of a midline section. Inferiorly it passes 3.7 to the left of the midline. It is difficult to distinguish cortical from trabecular bone due to irregular breakage, but cortex appears to average about 5 in anterior thickness and 7 across the superior transverse torus. The base shows a thickened cortex encircling a narrow trabecular area. The matrix filled bony canal opening through the supraspinous foramen (foramen supraspinosum) passes anteriorly into the trabecular space at midcorpus level. The symphyseal angle is roughly $50^{\circ}$.

D. Posterior aspect. The superior portion of post-incisive planum (planum alveolare) is lost to alveolar breakage and resorption. The planum is narrow and strongly concave, hollowed along sagittal and transverse axes. In occlusal view it terminates posteriorly in a superior transverse torus at the level of $\mathrm{P}_{3} / \mathrm{P}_{4}$. This torus is evenly rounded and does not overhang the genioglossal area, but forms its anterior wall. A round 0.8 diameter foramen supraspinosum is centered at the midline in the anterior fossa wall, 15.0 above the basal contour on a direct midline measure. In true occlusal view, the midlines defined by the foramen and that across the superior transverse torus do not coincide exactly, the mandible being slightly asymmetric in this region. Inferior to the foramen and dividing the fossa into lateral halves is a thin median ridge of bone represent ing the crest between genioglossus muscles ( $m$. genioglossi) whose roughened insertions occupy most of the fossa floor on either side of the midline. The median crest inverts posteriorly to become a groove between two raised tubercles adjacent to the midline which constitute the mental spines (spinae mentales). These represent insertions of the geniohyoideus muscles $(m$. geniohyoidei) and are flanked on either side by a single small nutrient foramen. The right spine measures roughly 4 in height, 2 in width and elevation, and is slightly smaller but sharper than the left. These spines are sited on the superior aspect of the inferior transverse torus which extends to the level of distal $P_{4}$ in occlusal view. The two toral structures are best seen in symphyseal cross section.

E. Medial aspect. The alveolar margin is best preserved on the right where it is straight from distal $M_{1}$ to $M_{3}$. The mesiolingual portion of mesial $M_{1}$ root interrupts this smooth margin and causes a pronounced bulge on the alveolar portion of the medial corpus. Anterior to this interruption the alveolar margin is slightly re. sorbed, closely invests the roots of $P_{3}$ and $P_{4}$, and bears a scatter of microforamina. The canine root is located about 2 anterior to its lingual alveolar rim, the displacement possibly linked to the pathological reaction described above. The lateral edges of the planum alveolare are slightly roughened. Besides these slight bony roughenings and the medial $M_{1}$ root bulge, the medial corpus is fairly smooth, with evenly rounded contours. There is no torus mandibularis or striated alveolar margin. The alveolar prominence is not particularly proturberant and the alveolar swelling is nearly continuous with the lateral extent of the superior transverse torus. The lateral ex- 
pression of the inferior transverse torus is strongest on the right corpus, where it passes posterosuperiorly to merge with the alveolar prominence at the $\mathrm{P}_{4} / \mathrm{M}_{1}$ level. The alveolar prominence is wide in vertical extent at this point but diminishes posteriorly to virtual nonexistence medial to $\mathrm{M}_{3}$.

A mylohyoid line (linea mylohyoidea) representing the posterosuperior $m$. mylohyoideus insertion passes anteroinferiorly from its broken terminus 3.9 below the alveolar margin at $M_{3}$ to disappear 15.0 below the margin at mesial $\mathrm{M}_{2}$. The line consists of a slightly indented roughening of the bony surface which averages about 2 in width. The line is continuous (through an intermediate patch of slightly roughened bone) with a weak anterior subalveolar fossa (fossa sub. alveolaris anterior) below the $M_{1}$ position. A slight narrow groove is located below and passes nearly parallel to the mylohyoid line. It converges with and passes about 5 anterior to the line's anterior terminus, lying about 4.3 below the midportion of the mylohyoid line on both sides and appearing incipiently double on the right. It diminishes posteriorly and is broken away below distal $\mathbf{M}_{3}$. A slight posterior subalveolar hollow. ing (fossa subalveolaris posterior) is present below the alveolar prominence at $\mathrm{M}_{3}$. As with the lateral corpus, weathering split-line cracks tend to follow longitudinal contours of the medial mandibular corpus.

F. Internal corpus morphology. The oblique fractures of posterior corpi prevent accurate metric assessment of mandibular canal position. It is clearly visible just below the mesiolingual $M_{3}$ socket apex on the left. Here it is roughly 2.8 in diameter and irregular in section. On the right, the canal is sectioned longitudinally and appears to reflect in the grooved mesial and distal $M_{3}$ root tips.

G. Basal aspect. The overall shape of the basal contour is a wide parabola. Viewed basally at $90^{\circ}$ to the occlusal plane, the broad rounded anterior portion projects strongly anterior to the basal contour. The base is evenly rounded beneath the molar row, slightly steeper laterally and more continuous with the medial corpus walls. The transition from anterior to posterior symphysis across the midline is smooth, with gnathion located on a rounded basal contour. This smooth transitional zone is interrupted on both sides of the midline by sharp, elongate basal tuberosities representing the inferior extent of the anterior marginal tubercle. The distance between anterior margins of these raised basal tuberosities is 8.0 , the left pair member approaching to within 2 , and the right to within 6 of the midline. These raised roughened ridges constitute the basal contour and account for its irregularity lateral to the midline. The ridge on the right is least pronounced and consists of two regions of tuberosity. The lateral extent of the bulging anterior marginal tubercle is more continuous with the narrow basal ridge on the left. The roughened posteromedial walls of these elevated basal tuberosities are slightly hollowed and constitute the digastric fossae. The areas immediately posterosuperior to the posterior basal ridge termini bear small $(7 \times 3)$, elongate hollows presumably representing posterior portions of the digastric fossae. These are limited superiorly by small tori below the anterior subalveolar fossae.

H. Occlusal aspect. The premolar/molar row is arranged along fairly straight axes on either side. An axis taken from mesial $P_{3}$ crown center to distal $\mathrm{M}_{3}$ crown center passes about 1.8 lingual to the $M_{1}$ crown center and demonstrates slight lateral convexity of the tooth row. The broken canine is set roughly 2 medial to the projected axis, but the complete crown probably projected slightly more laterally. The anterior dentition and alveolar margin are missing and damaged, precluding accurate assessment of the anterior dental arcade shape. The bi-canine internal alveolar breadth is slightly greater than half that estimated at $\mathrm{M}_{3}$, indicating strong anterior tooth row convergence. The empty central incisor alveoli are placed between and anterior to those of the lateral incisors. This provides indication that the anterior contour of the dental arcade was not flat but convex between the large canine crowns. In true occlusal view, depressions of the lateral corpus above the mental foramina are overhung by the buccal $\mathrm{P}_{4}$ crown faces. The lingual crown face of the $\mathrm{M}_{3}$ overhangs the medial contour of the right corpus. The basal contour and alveolar arch superimpose in this aspect at the $M_{1}$ level.

II. The dentition

A. The permanent lower dentition. 1. Permanent canine. The left crown and superior canine root are missing. The entire right canine

TABLE 6

Selected mandibular measurements: L.H. 4

-Bi-internal alveolar margin breadth at:

$\bar{C}: 21 \pm 1, \mathbf{P}_{3}: 30, \mathbf{P}_{4}: 35, \mathbf{M}_{1}: 30, \mathbf{M}_{2}: 36, \mathbf{M}_{3}: 41 \pm 1$

-Bi-basal contour breadth perpendicular to the alveolar margin below:

$P_{3}: 14, P_{4}: 37, M_{1}: 47 \pm 1, M_{2}: 67 \pm 3$

-Minimum parallel breadth of corpus perpendicular to long axis at

Symphy sis : 19.1

Right: $\bar{C}: 19.0, P_{3}: 18.3, P_{4}: 17.6, M_{1}: 19.6$

Left: $\bar{C}: 19.0, \mathbf{P}_{3}: 18.6, \mathbf{P}_{4}: 17.4, \mathrm{M}_{1}: 19.2, \mathrm{M}_{2}: 22.4$

-Direct corpus height perpendicular to the alveolar margin at:

Symphysis : $39 \pm 4$

Right: $\mathbf{P}_{3} / \mathbf{P}_{4}: \mathbf{3 8 . 3}, \mathbf{P}_{4}: 34.0, \mathbf{P}_{4} / \mathbf{M}_{1}: \mathbf{3 4 . 6}$

Left: $\quad \mathbf{P}_{3} / \mathbf{P}_{4}: 38.3, \mathbf{P}_{4}: 35.3, \mathbf{P}_{4} / \mathbf{M}_{1}: 34.2, \mathbf{M}_{1}: 31.4, \mathbf{M}_{1} / \mathbf{M}_{2}: 30.0, \mathbf{M}_{2}: 29.5$

-Bi-inner rim of mental foramina : 43.9 . 
crown apex is missing, but enamel fragments of labial, distal, and lingual faces are preserved. Crown shape is an elongate oval whose axis crosses the alveolar contour from mesiolabial to distolingual. Enamel preserved on the labial crown face includes the enamel line and tapers smoothly onto the root with little basal bulging. The distal enamel patch retains a posterior cingulum defined as a small cusp by distolabial and distolingual grooves. It seems continuous with the distal occlusal crown edge through a rounded ridge. The cingulum represents the most distally placed crown enamel but bears no trace of an interproximal facet for $\mathrm{P}_{3}$. The state of wear, overall crown height and profile are indeterminate. A large mesiodistally compressed root bears a slight mesial groove and measures $7.3 \times 10.3$ at the base of the enamel line. Its distal tip is obscured by investing mandibular bone, but a measurement from labial enamel line to apex is estimated at 25

2. Permanent third premolar. The $P_{3}$ is represented by broken roots on the left and intact crown on the right. Occlusal crown shape is an irregular ovoid whose long axis passes from mesiobuccal to distolingual at a steep angle to the tooth row axis. The crown is rounded by wear, with a mesiodistally elongate island of dentine exposure at the major buccal cusp apex and a smaller circular patch on the lingual cusp. Smooth wear extends across the entire buccal face and barely visible vertical wear striae mark this area. There is a 4.6-wide interproximal occlusal contact with the $P_{4}$, but no mesial facet for the $\bar{C}$.

A dominant, large buccal cusp is set just buccal to and mesiad of the crown center. A smaller, low lingual cusp is set lingual to the crown center and just distad of the buccal cusp level. A strong mesial buccal groove defines a rounded mesial ridge. A weak distal buccal groove defines the talonid buccally. Neither buccal groove reaches the crown base. This base as defined by the enamel line passes mesioinferiorly with respect to the alveolar margin, creating a vertically and horizontally extensive crown face. The lingual crown face bears a depressed area instead of a groove. Occlusally, strong crests run mesiad and distad of the buccal cusp and a transverse crest joins buccal and lingual cusps. A deep, pitlike anterior fovea is placed mesiad of the lingual cusp and lingual to the anterior crest of the buccal cusp. Most primary and all secondary fissuration is lost. A large mesiodistally compressed root is placed at a slight distolingual angle to the long axis of the tooth row and a smaller, more cylindrical anterior root diverges from it in a mesiobuccal direction.

3. Permanent fourth premolar. This tooth is shaped as a trapezoid with anterobuccal corner rounded and extending furthest mesially. Wear on right and left is similar, the right featuring a bilobed dentine patch on its buccal side measuring 7.6 mesiodistally, 3.4 and 1.0 across the lobes. A small, circular dentine exposure is seen on the mesiolingual crown corner. Fine, buccolingually oriented wear striae are barely visible. There are wide interproximal contacts with $P_{3}$ and $M_{1}$. Heavy wear obscures exact placement and relative cusp height, but major lingual and buccal cusps are placed mesiad of the crown center. A wide talonid is placed primarily on the distolingual crown quadrant. The lingual crown face is steep, the buccal face bulging and rounded. Well defined posterior and weaker anterior buccal grooves do not reach the enamel line. Root morphology is obscured by investing mandibular bone, but incipient bifurcation visible below the crown suggests distal and mesial roots whose division does not reach the alveolar level.

4. Permanent first molar. Crown outline is roughly square, with steep lingual and slightly more sloping buccal crown faces. Wear is heavy, particularly on the right. Protoconid, hypoconid and hypoconulid exposures have fused to produce an irregular, cupped strip of dentine exposure covering most of the buccal occlusal surface. On the left, dentine exposures at these cusp positions are isolate. The right entoconid displays an isolated patch of dentine slightly smaller than that on the metaconid, and only incipient exposure is seen here on the left. Enamel surfaces adjacent to these exposures are flattened with wear. Contact facets for $P_{4}$ and $M_{2}$ are developed on the left side to buccolingual lengths of 6.5 and 5.8 respectively. Wear striae are barely visible buccally and take a general buccolingual orientation.

The buccal groove is limited in vertical extent and appears to have ended abruptly in a pit now located at the occlusal rim between protoconid and hypoconid. The lingual groove is more pronounced, nearly reaching the enamel line. This line projects sharply inferiorly at midcrown level between mesial and distal buccal root lobes. Most primary fissuration is obliterated. Five major cusps are seen, these presumably arranged in a Y-pattern. The left side preserves traces of a lingually placed posterior fovea. The enamel line bears sharp inferior projections at mesial and distal root division positions on buccal and lingual crown faces. There are two roots which lie beneath mesial and distal crown positions, each mesiodistally compressed. The mesial root is widest buccolingually. Its lingual angulation causes a pronounced bulge in the medial alveolar portion of the mandibular corpus. The distal root is smaller and slants buccally, In occlusal aspect, mesiolingual and distobuccal portions of mesial and distal roots are plainly visible, while mesiobuccal and distolingual portions are hidden be neath the crown.

5. Permanent second molar. The left $M_{2}$ is more intact, the buccal portion of the right crown damaged. The crown is a slightly expanded version of the $M_{1}$, retaining the same basic square occlusal shape. As in $M_{1}$, the right $M_{2}$ displays heavier wear. The left crown shows roughly circular dentine exposures arranged in size from largest to smallest on protoconid, hypoconid and metaconid. All cusps are rounded by wear. Much primary fissuration is obliterated. There are wide mesial and smaller distal interproximal wear facets for the first and third molars respectively. Wear striae preserved on both crowns display overall buccolingual directional components and are most marked on protoconid and hypoconid. Five major cusps are arranged in a Y-pattern. There is a strong buccal groove continuous occlusally with the protoconid/hypoconid fissure, and a slightly weaker lingual groove. The left side dis- 
TABLE 7

Dental measurements: L.H.-4

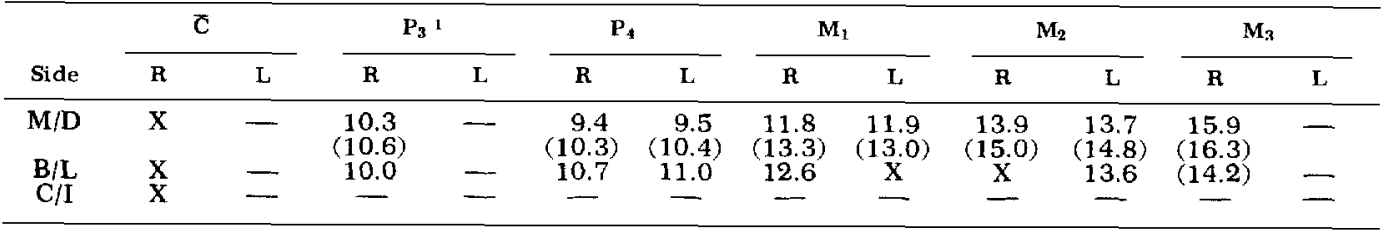

${ }^{1} P_{3}$ profile difficult to accommodate in measurement scheme used. Maximum long axis $=12.2$, minimum short axis $=9.8$

plays remains of a pit or small groove on the mesiobuccal protoconid corner representing a protostylid effect. Two major roots are placed as in $M_{1}$, with slightly less mesiolingual and more distobuccal projection in occlusal a spect.

6. Permanent third molar. The $\mathbf{M}_{3}$ is larger and more elongate than the $M_{2}$. The occlusal aspect reveals a rounded talonid profile contributing to this effect. The crown is moderately worn, displaying a small dentine exposure on the protoconid. The cusp apices of metaconid and less elevated entoconid are fairly sharp, and flat wear slopes buccally into the central crown area. The buccal face is evenly sloping, continuous with the rounded, worn protoconid and hypoconid. There is a concave, 5.1-long mesial interproximal facet for the $\mathbf{M}_{2}$. Central and distal buccal grooves are present, the former continuous occlusally with the fissure between protoconid and hypoconid. Much buccal crown enamel is affected by mild chemical weathering, and a protostylid groove effect is present. The distobuccal crown face is similarly affected, but a cleft continuous with the occlusal hypoconid/hypoconulid fissure passes partially onto this face.

The protoconid was the largest cusp and the entoconid and hypoconulid the smallest. Clear cusp demarcation is lost as wear has obliterated most primary fissuration. There are five major cusps, with probable metaconid/hy poconid contact indicative of a Y-pattern. Part of the secondary fissuration is preserved on the distolingual metaconid face and mesiolingual entoconid face. These remains imply a fairly crenulate crown pattern for the remainder of the tooth prior to wear. There are two strongly developed roots. The mesial root is invested in mandibular bone but appears mesiodistally compressed and is placed below the two major mesial cusps. The posterior root is exposed distally and is highly divergent distobuccally. It takes the shape of a curved, tapering cylinder with marked distal buccal groove. It measures 11.4 in total length inferior to the enamel line along the groove axis.

LAETOLIL HOMINID 5: Locality 8 (plate 5G-J; table 8)

Specimen consists of: Right maxillary row $\mathrm{I}^{2}$ to $\mathrm{M}^{1}$.

Preservation: The specimen consists of a dental row with teeth in proper anatomical relationship. The tooth roots are embedded in weathered remains of maxillary bone. Except for the canine, the teeth have been subjected to breakage and display varying amounts of enamel loss. The maxillary bone shows virtually no original surface or meaningful morphology.

Morphology :

1. The dental arcade. The canine, premolars and first molar are set in a fairly straight line, their orientation with respect to the sagittal plane unknown. The gap between distal $I^{2}$ and mesial $C$ is due largely to breakage of the distal $I^{2}$ crown. This space would probably have been virtually absent, but an interproximal facet is not on the mesial canine enamel surface. The angle between the mesiodistal $I^{2}$ axis and that of the $\underline{C}$ to $M^{1}$ row is approximately $30^{\circ}$. The $I^{2}$ root angles posteriorly, its apex set medial to the mid-canine root position.

II. The dentition.

A. The permanent upper dentition. 1. Per manent lateral incisor. Only the lingual crown face is preserved. Mesial and distal faces are entirely missing and only a small flake of labial enamel near the incisal surface remains. The tooth is worn, with 1.0-wide strip of dentine exposed mesiodistally along the incisal margin. The gingival eminence is surmounted by the trace of a broken distal lingual ridge. The labial enamel flake bears a roughened, striated patch incisal to a smooth enamel surface. This interruption probably represents hypoplasia. The root is compressed mesiodistally, measuring $4.2 \times 6.3$ at the base of the gingival eminence. Its length distal to the lingual enamel line is 14,8 .

2. Permanent canine. The occlusal shape is oval, with long axis directed mesiobuccal to distolingual. The apex, occlusal edges and lingual aspect show wear. A $1.0 \times 6.0$ rectangular patch of exposed dentine passes just lingual to the distal occlusal ridge from apex to posterior cingulum. A flat, polished occlusal surface is present across the mesial occlusal crown edge. Most of the lingual face is polished by wear and bears microscopic striae crossing the enamel surface perpendicular to the occlusal row. The labial face is heavily worn but displays a bulging base. Weak mesial and distal marginal ridges form labial aspects of anterior and posterior cingula. The apex is blunted and the original crown profile obscured by wear. A gingival eminence is present, surmounted mesially by a strong, rounded mesial lingual ridge in turn flanked distally by a deep mesial lingual groove. This groove demarcates the anterior cingulum which appears to have risen to a higher unworn elevation than the posterior cingulum. Remains of the posterior cingulum are obliterated by wear, but a distal marginal ridge 
TABLE 8

Dental measurements: L.H.-5

\begin{tabular}{|c|c|c|c|c|c|c|c|c|c|c|}
\hline \multirow[b]{2}{*}{ Side } & \multicolumn{2}{|c|}{12} & \multicolumn{2}{|c|}{$\underline{\mathrm{C}}$} & \multicolumn{2}{|c|}{$\mathrm{P}^{3}$} & \multicolumn{2}{|c|}{$\mathrm{P}_{4}$} & \multicolumn{2}{|c|}{$M^{1}$} \\
\hline & R & $\mathrm{L}$ & $\mathrm{R}$ & $\mathbf{L}$ & $R$ & $\mathbf{L}$ & $\boldsymbol{R}$ & $L$ & $\mathbf{R}$ & $\mathbf{L}$ \\
\hline $\mathrm{M} / \mathrm{D}$ & $\mathrm{X}$ & - & $\begin{array}{c}9.6 \\
\text { worn }\end{array}$ & - & $\begin{array}{c}7.7 \\
(8.9)\end{array}$ & - & $(9.1)$ & - & $\mathrm{X}$ & - \\
\hline$B / L$ & $X$ & - & 9.8 & - & $\mathrm{X}$ & - & $\mathrm{X}$ & - & $X$ & - \\
\hline $\mathrm{C} / \mathrm{I}$ & $X$ & - & X & - & - & - & - & - & - & - \\
\hline
\end{tabular}

and groove were probably present. The entire lingual aspect is worn to low rounded relief and the dominant remaining features are the mesial lingual ridge and elongate, sloping patch of dentine exposure. The labial face is encircled by strong perikymata which degenerate at mid-crown into deep roughened lines, a larger occlusal and smaller basal one apparently representing hypoplastic episodes 5.8 and 4.0 above the enamel line. The canine root is slightly compressed mesiodistally, measuring $7.1 \times 9.0$ at the enamel line. It curves slightly distad to its apex 20.6 from the labial enamel line.

3. Permanent third premolar. Occlusal crown shape is an elongate oval compressed mesiodistal. ly. The lingual crown face has lost the enamel coat and is represented by the dentine core while the buccal enamel line is missing. Wear is heavy, with a $3.0 \times 5.0$ patch of cupped dentine exposure in the area once occupied by the major lingual cusp. The buccal cusp apex bears a tiny dentine exposure. The entire buccal cusp is polished and rounded by wear, with buccolingually directed microscopic striae. There is a 3.3 interproximal contact with the $\underline{\mathrm{C}}$ and a larger broken contact with the $P_{4}$. The buccal crown face bears a small portion of mesial buccal ridge. There appear to have been major buccal and lingual cusps, the latter placed slightly mesiad of the buccolingual crown axis. Remains of primary and secondary fissuration are largely obliterated by wear. The buccal face shows two distinct, indented, roughened lines in the enamel passing horizontally around the crown face. These are located 4.4 and 5.7 above the enamel line position and represent hypoplastic episodes. Major cylindrical roots are placed under lingual and buccal cusp positions. Their apices are broken, the buccal root length estimated at 13 from the enamel line position.

4. Permanent fourth premolar. This tooth is of similar shape to the $P^{3}$, with buccal cusp placed more mesiad of the major tooth axis to give the tooth a slightly more "bent" appearance. The lingual enamel surface and buccal enamel line are missing. The tooth is slightly more worn than the $\mathrm{P}^{3}$, with a larger cupped patch of dentine exposure covering the entire lingual crown half and a much smaller, 1.0 diameter patch exposed at the buccal cusp apex. As with the $\mathrm{P}^{3}$, the enamel rim encircling the lingual crown edge is broken. The damaged buccal crown face is a rounded, featureless surface. Occlusal fissuration is obscured by wear, but major buccal and lingual cusps were present. Wear striae cross the oc- clusal enamel surface of the buccal cusp as in P3. A pitted line of hypoplastic activity on the buccal crown face about 5 above the enamel line position is partially obscured by wear. Roots of similar placement and dimension to the $P 3$ are exposed. The buccal root bears a deep median buccal cleft and is complete to its apex, measur. ing about 12 distal to the enamel line position.

5. Permanent first molar. This tooth is heav. ily damaged, retaining only two small occlusal enamel flakes. One is between the paracone and metacone positions and the other on the lingual rim, extending onto the lingual crown face. Wear is extensive, creating a continuous L-shaped depressed dentine exposure passing distally and buccally from the protocone position. Only the dentine core remains in the metacone area and this preserves portions of a dentine exposure. Microscopic wear striae cross the lingual occlusal enamel surface buccolingually. A trace of primary fissuration is evident as a weak groove preserved on the enamel fragment between paracone and metacone positions. There are three major roots.

Two small buccal roots are slightly mesiodistally compressed while the larger, more divergent lingual root is rounded and bears a slight lingual groove. Apices of mesiobuccal and lingual roots are damaged, but the distobuccal root measures approximately 10.0 from apex to estimated crown line.

LAETOLIL HOMINID 6: Locality 7 (plate 5E; table 9)

Specimen consists of: Isolated teeth: (a): $\mathrm{RI}^{2}$, (b): $\mathbf{R C}$, (c): RP3, (d): $\mathbf{R d M}^{2}+\mathbf{P}^{4}$, (e): $\mathbf{R M}^{1}$

Preservation: Refer to L, H,-3 for details of association. The $\mathrm{dM}^{2}$ roots adhere to maxillary bone residue and the unerupted $\mathrm{P}_{4}$ crown is at tached to this fragment. The $I^{2}$ and $M^{1}$ also retain small patches of maxillary bone, but other teeth are isolate.

Morphology:

I. The dentition.

A. The deciduous upper dentition. 1. Deciduous second molar: L.H.-6(d). The crown suffers major cracking. Loss of buccal and distal crown faces makes determination of relative crown shape and proportion impossible. A large dentine exposure occupies the protocone. A mesial interproximal facet for the $\mathrm{dM}^{1}$ is present but broken. A wide lingual groove lies between protocone and hypocone. Most primary fissuration is broken or worn away, but an oblique crest joins protocone and metacone. The posterior fovea seems well defined. The anterior fovea consists of a buccolingually oriented fissure just distad of the mesial occlusal edge, 
passing mesiad of the protocone and paracone and interrupted midway by dentine exposure. There are two buccal roots and a single large and very divergent lingual root. The buccal roots measure about 10 in length below the respective enamel line positions, with hints of resorption. The unerupted P4 crown lies between these roots, centered below the $\mathrm{dM}^{2}$ crown.

B. The permanent upper dentition. 1. Permanent lateral incisor: L.H.-6(a). This unerupted crown is similar in size and shape to L.H.-3(c), but morphological details divide the two individuals. The labial face is smooth and convex, lacking grooves or ridges. Mesial and distal crown faces are rounded, bearing no grooves. The mesial incisal edge is a fairly sharp corner, the distal in. cisal edge rounded with no clear demarcation of incisal and distal margins. The incisal edge is sharp, bearing three well defined mamelons. The lingual incisal ridge is set about 1.0 inferior to the incisal edge, passing parallel to this edge. The lingual face is concave, bounded by mesial and distal marginal ridges. There are no median lingual ridges and the gingival eminence, although broken, is not pronounced. There is no lingual tubercle. The crown is complete, with a damaged developing root.

2. Permanent canine: L.H.-6(b). The unerupted crown is fully formed, with nearly intact enamel line and proximal portions of developing root. The crown is smaller in size and presents a different shape and morphology than L.H.-3(e). The labial face is smooth, strongly convex mesiodistal. ly, and less so cervico-occlusally. The posterior cingulum is broken but as judged from the dentine core does not appear to have been particularly prominent. An incipient mesial labial groove defines the anterior cingulum. Presence of a distal labial groove is indeterminate. The crown tip is fairly narrow and the shape in labial view asymmetric, with the distal crown edge slightly convex and the mesial slightly concave. The lingual face presents the most relief but still far less than L.H.-3(e). A rounded lingual ridge is placed mesiad of the crown center, passing from anterior gingival eminence to crown apex. Distad of this ridge the crown face is slightly roughened by weak crenulations but major ridges are absent. The distal gingival eminence and possible traces of posterior cingulum are lost. The anterior cingulum is a strong accessory capsule originating from the anterior gingival eminence. Between the lingual ridge and anterior crown margin a mesial lingual groove ends in a cleft at mid-cingulum level. The gingival eminence is moderately protuberant and poorly deflned from the rest of the lingual face. Fine perikymata encircle the crown.

3. Permanent third premolar: L.H.-6(c). The unerupted, fully formed $P_{3}$ crown has an occlusal shape similar to that of L.H.-3 (f). Of two major cusps, the buccal is slightly larger and elevated about 2 above the lingual relative to the crown base. The cusps are tall and sharp. The lingual cusp is skewed mesiad of the buccolingual crown axis and the mesial crown profile has a "bent" appearance owing to the concavity in the mesial occlusal crown edge. The lingual crown face is slightly more sloping than the buccal and lacks major relief. There are strong mesial and weaker distal buccal grooves. Primary fissuration is $\mathrm{H}$ - shaped, with mesiolingual arm poorly developed, and the anterior fovea consequently situated largely buccally. A central fissure divides major buccal and lingual cusps. The posterior fovea is well developed, defining a moderate talon without accessory cusps. Secondary fissuration is moderately developed, giving the occlusal surface a slightly crenulate appearance. Root formation has just begun, and thin root projections skirt the base.

4. Permanent fourth premolar: L.H.6(d). Only the $P^{4}$ base and a small portion of lingual crown are visible, the occlusal crown aspect obscured entirely by $\mathrm{dM}^{2}$ roots, maxillary bone, and matrix. The crown appears to be an elongate oval shape and is fully developed. Root formation is in progress. The natural mold of the distal $\mathrm{P}^{3}$ face in adhering matrix below the crown at midroot $\mathrm{dM}^{2}$ level shows the $\mathrm{P}^{3}$ to have passed its apex through the alveolar interface premortem.

5. Permanent first molar: L.H.-6(e). Crown shape is nearly identical to that of L.H.-3(h,i), but the crown is slightly smaller. The protocone is dominant in occlusal area, the paracone and metacone of smaller, roughly equal size, and the hypocone the smallest cusp. The crown is widest lingually, the distal crown face converging buccally with the mesial. Wear has rounded the protocone and polished and facetted other major cusps. A small oval $\mathrm{dM}^{2}$ contact facet occupies the mesial face. The occlusal surface is pitted by mechanical erosion and flaking on buccal cusp apices appears to represent postmortem-damage. The buccal cusps are about 1.5 higher than the lingual ones relative to the crown base. Single lingual and buccal grooves end roughly halfway down the respective crown faces. The mesiolingual protocone corner bears a deep indented pit repre senting the Carabelli trait. A weak ridge and groove on the mesiobuccal paracone corner represent a parastyle effect. A strong oblique crest connects protocone and metacone, and a weaker crest joins protocone and hypocone. A mesiodistally elongate, buccally placed anterior fovea rests mesiad of a weak transverse crest between protocone and paracone. The buccal arm of the triradiate central fovea is continuous with the buccal groove across a weak paracone/metacone crest. The oblique fissure bifurcates distally, forming a small but deep posterior fovea with two small cuspules on its distal rim. Fine perikymata encircle the crown base, and some roughened patches on the lingual protocone face probably represent hypoplasia in addition to mechanical weathering.

Of three roots, two are placed buccally below metacone and paracone and one is placed lingual to the crown center and slightly more divergent with respect to the crown axis, bearing a single lingual groove. Root apices are not entirely closed and are partially encased in maxillary bone. The maxillary sinus floor reaches a level below the root tips.

LAETOLIL HOMINID 7: Locality 5 (plate 5B table 1)

Specimen consists of: Fragment of RM-

Preservation: Nearly the entire enamel surface is missing. All three roots are broken.

Morphology: Only a small fragment of mesial enamel face remains of the crown sides. This 
TABLE 9

Dental measurements: L.H.-6

\begin{tabular}{|c|c|c|c|c|c|c|c|c|c|c|c|c|}
\hline \multirow[b]{2}{*}{ Side } & \multicolumn{2}{|c|}{$\mathrm{dM}^{2}$} & \multicolumn{2}{|c|}{12} & \multicolumn{2}{|c|}{$\underline{\mathrm{C}}$} & \multicolumn{2}{|c|}{$P^{3}$} & \multicolumn{2}{|c|}{$P_{4}$} & \multicolumn{2}{|c|}{$\mathrm{M}^{1}$} \\
\hline & $\mathbf{R}$ & $\mathrm{L}$ & R & $\mathbf{L}$ & $\mathbf{R}$ & $\mathrm{L}$ & $\mathbf{R}$ & $\mathbf{L}$ & $\mathbf{R}$ & $\mathbf{L}$ & $\mathbf{R}$ & $\mathbf{L}$ \\
\hline $\mathrm{M} / \mathrm{D}$ & $X$ & - & 7.8 & - & $(10.1+)$ & - & $(9.3)$ & - & $\mathrm{X}$ & $\ldots$ & 11.9 & - \\
\hline $\mathrm{B} / \mathrm{L}$ & $\mathbf{X}$ & $\longrightarrow$ & $(7.4)$ & - & 10,0 & - & 13.0 & - & $\mathrm{X}$ & - & 14.0 & 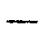 \\
\hline C/I & 一 & - & $(10.9)$ & - & 13.4 & - & $\longrightarrow$ & $\cdots$ & - & - & - & - \\
\hline
\end{tabular}

bears a fragment of interproximal facet for $\mathrm{P}^{4}, \mathrm{M}^{1}$ or $\mathrm{M}^{2}$. Enamel on buccal, lingual and distal crown faces is missing, exposing a dentine core with a $5 \times 7$ patch of adhering occlusal enamel. Primary fissuration remnants show an oblique crest broken by a groove passing between protocone and metacone. The oblique groove between metacone and hypocone appears moderately developed. A weak crest apparently joined protocone and paracone. Occlusal wear is fairly flat. No dentine exposure is preserved. One lingual root and two buccal roots are present. The distal buccal root is smallest and more divergent, the lingual larger. Both buccal roots are mesiodistally compressed. The lingual root is oval, compressed buccolingually, and divergent.

LAETOLIL HOMINID 8: Locality 11 (plate 5F; table 1)

Specimen consists of: Isolated teeth: (a): $\mathrm{RM}^{2}$, (b): $\mathrm{RM}^{3}$.

Preservation: Most $\mathrm{M}^{2}$ enamel has been lost and the mesiobuccal corner and root of $\mathrm{M}^{3}$ are missing. All $\mathrm{M}^{2}$ roots are damaged.

Morphology:

A. Permanent upper dentition. 1. Permanent second molar: L.H.-8(a). The crown appears to have been widest across the lingual cusps. The mesiobuccal angle is strongly protuberant. The crown is heavily worn. A continuous groove of dentine exposure 1.0 in depth and 2.3 to 5.5 in width crosses the lingual occlusal surface. This exposure expands to widest extent in the area usually occupied by the protocone and again but to a more limited extent in the hypocone area. The paracone has a small, 1.3 diameter patch of dentine exposure, and it is uncertain whether the metacone had as well. Basal portions of interproximal facets for $M^{1}$ and $M^{3}$ are located on broken mesial and distal crown faces. Primary fissuration is obliterated by wear and only the paracone/metacone division remains on the flat occlusal surface. Poorly developed lingual and buccal grooves are present, but only the basal portions are preserved. The two buccal roots are mesiodistally compressed and directed posterosuperiorly with respect to the occlusal surface. A single larger lingual root is present, bilobed in section, with a deep rounded lingual groove.

2. Permanent third molar: L.H. -8(b). Occlusal crown shape is a rounded triangle with hypotenuse placed mesially and apex distally. The crown is heavily worn, with a $2.6 \times 4.0$ patch of dentine exposure at the protocone position. Primary fissuration is largely obliterated, but enough remains to demonstrate the protocone as the largest cusp. A broken contact facet for the $M^{2}$ marks the mesial crown face. A weak oblique crest joins protocone and metacone. Basal portions of weak buccal and lingual grooves are present. The posterior fovea appears poorly developed, existing only as a distal extension of the oblique groove which crosses the posterior rim of the tooth to produce a weak groove on the distal face. Two micropits on the mesiolingual protocone corner probably do not represent the Carabelli trait because of their low position. The distal occlusal margin bears several small step fractures, the polished edges of which probably indicate premortem origin. The protocones of both molars bear fine wear striae oriented buccolingually. Very fine perikymata are observed around the base of the teeth.

The $M_{3}$ root system consists of lingual and paired buccal roots. These are constricted basally but swell distally before tapering to their apices. The buccal roots are swollen and mesiodistally compressed. The distobuccal root is the smaller pair member. Its tip is slightly hooked beneath the crown. The lingual root is compressed buccolingually and bears a lingual groove. It also hooks slightly beneath the crown. The distal buccal root measures 12,0 and the lingual 13.0 below respective enamel line positions.

LAETOLIL HOMINID 10: Locality 10W (plate 6D-E)

Specimen consists of: Left mandible fragment with broken roots only of $\bar{C}$ to $\mathrm{M}_{1}$.

Preservation: The specimen is badly weathered with basal portion and tooth crowns missing. It retains the distal half of the $\bar{C}$ root and both mesial and distal $M_{1}$ roots. No alveolar margin remains.

Morphology

I. The mandible.

A. Lateral aspect. Mild chemical erosion affects most unbroken surface. A single round mental foramen opens nearly directly laterally, with a slightly superior directional component donated by sharp inferior and notched superior borders. The 3.7-diameter foramen rests immediately below the mesial $\mathbf{P}_{\mathbf{4}}$ root apex an indeterminate distance below the alveolar margin. The foramen occupies the base of a depressed alveolar portion bounded anteriorly by the bulging $P_{3} / \bar{C}$ jugae and inferiorly by a weak lateral superior torus which the foramen surmounts.

B. Medial aspect. Remains of a rounded alveolar prominence and the lateral reflection of what was apparently a sloping alveolar planum are observed in medial aspect. The small portion of unweathered cortex precludes further observation or quantification.

C. Internal morphology. The broken base reveals a sectioned, circular mandibular canal of 
about 3 diameter which passes anteriorly from its broken terminus about 6 medial to the external lateral corpus below $M_{1}$ to its opening via the mental foramen. Its course sweeps anterosuperior ly with a smooth lateral bend (reference to occlusal row and lateral corpus). roots.

A. The canine. The canine root is set obliquely to the corpus axis, appears mesiodistally com. pressed, and measures an estimated 10 along its labiolingual axis as unknown distance below the alveolar margin.

B. The third premolar. The distal $\mathrm{P}_{3}$ root tip remains. The root appears single as broken.

C. The fourth premolar. The $\mathrm{P}_{4}$ root is incipiently bifurate distally, and only broken apices remain. A roughened depression in the alveolar bone lies between lingual portions of $P_{3}$ and $P_{4}$ roots. Its origin is unknown.

D. The first molar. There are mesially and distally placed $M_{1}$ roots which show great mesiodistal compression. Each is bilobate, with buccal and lingual swellings. Buccolingual measurement of mesial and distal roots is 13.2 and 12.4 respectively, an unknown distance below the alveolar margin.

LAETOLIL HOMINID 11: Locality 10W. (plate 5C; table 1)

Specimen consists of: $\mathrm{LM}^{1}$ or ${ }^{2}$.

Preservation: The crown and root system are intact, with slight traces of mechanical abrasion on the crown edges.

Morphology:

I. Upper dentition.

A. Permanent molar. Overall crown shape is roughly square, with metacone corner pressed toward the crown center. Wear has rounded the entire protocone and hypocone surfaces, resulting in exaggerated elevation of the buccal cusps which bear occlusal facets and polishing. No dentine is exposed. Pressure step-flaking is seen along buccal paracone and metacone edges. Some of these macroflakes appear to represent premortem damage, the occlusal edges showing wear polish. Well preserved wear striae cross the occlusal surfaces of protocone and hypocone. The predominant direction is buccolingual, the striae just visible to the naked eye. A second set of microscopic striae is superimposed on and perpendicular to the first. A small $(1.5 \times 3)$, slightly concave interproximal facet occupies the mesial crown face. Its single nature and occlusal location sug. gest that the tooth represents a $M^{2}$ instead of a M1.

There are four major cusps, with protocone at least twice the size of either hypocone or paracone. The metacone is the smallest cusp. The tooth is widest across protocone and paracone, the mesiobuccal and mesiolingual angles most protuberant. The lingual face is more bulbous and sloping than the buccal. There are single weak buccal and lingual grooves. Below the damaged buccal paracone edge a distoinferiorly directed groove and ridge represent posterior expression of an incipient parastyle. Much secondary fissuration is obliterated by wear, but the primary system is intact. The oblique groove is continuous with lingual groove and small buccally placed posterior fovea. There is no oblique ridge, the protocone and metacone contacting across a transverse fissure joining central fovea and oblique fissure. The central fovea is triradiate, its anterior arm passing to a point between protocone and paracone and its buccal arm passing between paracone and metacone to join the buccal groove. The anterior fovea appears minor and is largely obliterated by wear. Hypoplastic pitting marks the edge of the hypocone, being especially prominent in a band 3.5 above the enamel line.

There are two mesiodistally compressed buccal roots and a larger, single buccolingually com pressed, slightly divergent lingual root. Root apices display nearly closed root canals. The mesiobuccal root bears a deep impression on its mesial face, giving it an indented aspect. The lingual root bears a weak lingual groove and consequently bilobed section.

LAETOLIL HOMINID 12: Locality 5 (plate 5D table 1)

Specimen consists of: Left $\mathrm{M}^{2}$ or ${ }^{3}$ fragment

Preservation: Only buccal and distal crown portions remain. Both buccal roots are nearly intact, the lingual broken.

Morphology: The divergent roots and crenulate crown suggest a permanent third molar. The protocone is occlusally dominant, followed by paracone, metacone and hypocone in decreasing size order. Wear is seen in large occlusal facets on protocone and paracone and as small facets and rounding on hypocone and metacone. The buccal groove is poorly developed and barely continuous with the buccal arm of the central fovea. A strong fissure separates protocone and metacone, joining central and posterior foveae. The posterior fovea is deep and extensive, with distal buccal and lingual arms separating the distal occlusal rim from metacone and hypocone. Secondary fissuration is deep, but not particularly extensive. There are larger mesiodistally compressed mesial and smaller round distal broken buccal roots. The lingual root is broken along with the lingual crown portion. Its size and shape cannot be assessed. The roots are incornpletely formed and bear wide root canals at their apices. Breakage through the crown center reveals a pulp chamber roughly 5.6 long and $3.8 \mathrm{high}$. Dentine thickness above this chamber averages 3.5 and unworn enamel thicknesses range from 1.6 to 2.3 .

LAETOLIL HOMINID 13: Locality 8 (plate 6A-B)

Specimen consists of: Fragmentary mandibular corpus with roots only of $M_{1}$ to $M_{3}$.

Preservation: The specimen has been subjected to intense weathering and no original surface re mains on the cortex. Some contour details are preserved and the lingual alveolar margin is only slightly abraded. The mesial $M_{1}$ root alveolus is seen in vertical anterior section, and half of the mesial $\mathbf{M}_{3}$ root is seen in the oblique posterior fracture surface. The base is entirely missing, exposing the sectioned mandibular canal.

Morphology:

I. The mandible.

A. Lateral aspect. The weathered ramus root remains as an artificially sharpened oblique line sweeping anteroinferiorly at an angle of about $45^{\circ}$ to the alveolar margin. This would have defined a superiorly placed, narrow extramolar sulcus lateral to $\mathbf{M}_{3}$, opening anteroinferiorly at the $\mathbf{M}_{2}$ level. In true lateral view, an anterior ramus border would have obscured all or part of the $\mathrm{M}_{3}$ crown. 
B. Medial aspect. A wide alveolar prominence was present, but weathering has obscured its shape and extent.

C. Internal morphology. The broken base exposes remains of the mandibular canal whose roof passes just inferior and medial to the distal tip of the mesiobuccal $M_{3}$ root apex. The canal sweeps evenly in an anteroinferior direction, its roof exposed near midcorpus width in the anterior fracture, approximately 20 below the alveolar margin and 6.7 below the mesiobuccal $M_{1}$ root apex.

II. The dentition. Represented only in broken roots.

A. The first molar. Two roots were present placed mesial and distal to the crown center and compressed mesiodistally.

B. The second molar. Mesial and distal roots are shaped as in $M_{1}$. Buccolingual measurements of mesial and distal roots at the alveolar level are 13.8 and 10.2 respectively. $A s$ in $M_{1}$, the mesial root is more elongate buccolingually and compressed mesiodistally. Lingual extension of the mesial root is pronounced over that of the distal root in both $M_{1}$ and $M_{z}$, but the root jugae do not appear to disturb the internal alveolar contour.

C. The third molar. Only the lateral portion of mesial $M_{3}$ root is preserved, the apex reaching about 14 below the alveolar margin.

LAETOLIL HOMINID 14: Locality 19 (plate 6C table 10)

Specimen consists of: Isolated teeth: (a): $\mathbf{R I}_{1}$, (b): $\mathbf{L I}_{1}$, (c): $\mathbf{R I}_{2}$, (d): $\mathbf{L I}_{2}$, (e): RC, (f): LC, (g): $\mathrm{LP}_{4},(\mathrm{~h}): \mathrm{RM}_{1}$ or $_{2}$

Preservation: All crowns have been subjected to some degree of mechanical and chemical weathering and vary in preservational status.

Morphology:

I. The dentition.

A. The permanent lower dentition. 1. Per manent central incisor: L.H.-14(a,b). The right $I_{1}$ is better preserved, but retains only root and a fragment of enamel on the lingual crown face. The left consists of root and an equivalent detached fragment of enamel. The lingual crown face is concave. The root shows strong mesiodistal compression and measures $4.3 \times 7.6$ at the enamel line. There are strong mesial and weak distal lingual grooves. Root length from apex to lingual enamel line is about 18 .

2. Permanent lateral incisor: L.H.-14(c,d). The lateral incisors are better preserved than the centrals. The left side retains minute enamel patches unaffected by chemical weathering or breakage as well as a complete root. The right shows a nearly intact crown. Occlusal shape is a mesiodistally compressed oval. Occlusal wear has exposed a 1.2-wide depression of dentine extending mesiodistally and bordered by raised labial and lingual lips. Broken, flat interproximal facets for the central incisor and canine are present on mesial and distal crown faces. The labial face is preserved only in distal extent and displays a smooth flat surface. The lingual face is largely etched by chemical weathering, but a moderate gingival eminence is surmounted mesially and distally by weak marginal ridges. The lingual crown face is concave. The mesiodistally compressed right $I_{2}$ root measures $4.0 \times 7.0$ at the base of the gingival eminence, the height from apex to this level being 16.6. The root bears mesial and distal grooves.

3. Permanent canine: L.H.-14(e,f). The permanent canines afford composite description as the left crown and right root are both nearly intact, the right root broken and the left crown chemically eroded. Overall crown morphology is similar to that described for L.H.-3 $(o, n)$. The tooth's occlusal outline is an oval compressed mesiodistally. Apical wear has exposed an irregular dentine patch of roughly 1.7 diameter. The occlusal plane defined by the enamel rim encircling this exposure slopes inferolingually at about $25^{\circ}$ to the crown axis. A polished triangular occlusal facet occupies the distal crown ridge, its base bordering the occlusal rim superiorly. The labial crown displays polished wear on its superior portion and vertical wear striae are visible here as well as in the distolabial groove. A large, flat, vertically oriented interproximal facet for $I_{2}$ marks the mesial face, measuring $2.3 \times 4.8$. The distal face displays a smaller, more curved but partially eroded facet for $P_{3}$. The labial face shows strong distal and weaker mesial grooves. The crown is asymmetric when viewed labially, the anterior cingulum only incipiently developed but more occlusally elevated than the distal. The lingual face displays strong mesial and distal grooves, the latter deep and V-shaped. These are separated by a strong but slightly worn lingual ridge extending from gingival eminence to occlusal edge. This ridge forms the vertical mesial wall of the distal groove but slopes more evenly into the wider mesial groove. The anterior cingulum consists of a strong mesial ridge while the posterior cingulum is more distinct, consisting of an accessory cusp defined by distal lingual and labial grooves. The gingival eminence is rounded and bulbous, surmounted by one central and two marginal lingual ridges. The basal two thirds of the labial crown face display marked hypoplastic activity in the form of enamel pocketing and pitting. The root is mesiodistally compressed, measuring $7.2 \times 10.0$ at the base of the gingival eminence. Its length is 23.5 from gingival emin ence base to root apex. There is a strong mesial groove and an evenly rounded distal root surface.

4. Permanent fourth premolar: L.H. $-14(\mathrm{~g})$. The occlusal crown surface is damaged by chem ical erosion. The shape is asymmetric, with protuberant mesiobuccal and distolingual corners. Wear has exposed a $1.8 \times 3.6$ patch of dentine at the major buccal cusp position. The major lingual cusp is represented as an elevated surface, but wear on the crown is flat, interrupted only by this cusp and the posterior fovea. The talonid appears extensive, and the posterior fovea re tains enamel with crenulate secondary fissuration in its depth. Remains of buccal and lingual grooves, if present, have been lost. A portion of mesial interproximal facet for $P_{3}$ is seen mesially, and the distal crown face shows portions of a wide flat interproximal facet for $\mathbf{M}_{1}$. There are two broken roots whose degree of continuity is unknown. The larger root is placed under the major buccal cusp and bears an incipient mesial division. The lingual root is placed squarely beneath the posterior fovea.

Permanent molar: L.H.-14(h). Whether the crown represents a first or second molar is uncertain, crown asymmetry and degree of wear suggesting the latter. The mesial crown rim is 
TABLE 10

Dental measurements: L.H.-14

\begin{tabular}{|c|c|c|c|c|c|c|c|c|c|c|}
\hline \multirow[b]{2}{*}{ Side } & \multicolumn{2}{|c|}{$I_{1}$} & \multicolumn{2}{|c|}{$\mathbf{I}_{\mathbf{2}}$} & \multicolumn{2}{|c|}{$\overline{\mathbf{C}}$} & \multicolumn{2}{|c|}{$\mathbf{P}_{4}$} & \multicolumn{2}{|c|}{$\mathrm{M}_{1}$ or $_{2}$} \\
\hline & $\mathbf{R}$ & L & $\mathbf{R}$ & I & $\mathbf{R}$ & L & $\mathbf{R}$ & $\mathbf{L}$ & $\mathbf{R}$ & $\mathbf{L}$ \\
\hline $\mathrm{M} / \mathrm{D}$ & $\mathrm{X}$ & $\mathbf{X}$ & $\begin{array}{l}5.7 \\
\text { worn }\end{array}$ & $X$ & $\mathrm{X}$ & $\begin{array}{r}9.3 \\
\text { worn }\end{array}$ & - & $\begin{array}{c}10.6 \\
(10.9)\end{array}$ & $\mathbf{X}$ & - \\
\hline $\begin{array}{c}\mathrm{B} / \mathrm{L} \\
\mathrm{C} / \mathrm{I}\end{array}$ & $\begin{array}{l}X \\
X\end{array}$ & $\begin{array}{l}\mathbf{X} \\
\mathbf{X}\end{array}$ & $\begin{array}{c}(7.6) \\
X\end{array}$ & $\begin{array}{l}X \\
X\end{array}$ & $\begin{array}{c}10.3 \\
\mathrm{X}\end{array}$ & $\underset{\mathrm{X}}{(10.1)}$ & - & 11.5 & $\underline{X}$ & - \\
\hline
\end{tabular}

broken and heavy weathering affects the distolingual tooth guadrant. Two patches of dentine exposure are present. The largest is circular, 2.3 in diameter, and placed in the area of the hypoconid. The second smaller patch occupies the hypoconulid position but is damaged. Wear is flat across most of the surface, but protoconid and metaconid positions appear somewhat elevated above the remaining occlusal surface. A weak interproximal facet occupies the distal crown face. Primary fissuration is obscured by wear and weathering. A weak groove crosses the buccal crown face and a lingual groove is placed between metaconid and entoconid. The enamel line dips in rounded basal projections between buccal and lingual divisions of mesial and distal roots. The two major roots are mesiodistally compressed, bilobed, with broken apex. The distal root has a twisted appearance due to exaggerated distobuccal projection of its buccal lobe.

\section{ACKNOWLEDGMENTS}

I thank Doctor M. D. Leakey for requesting me to provide descriptions of the Laetolil hominid remains. The permission of the United Republic of Tanzania to work the Laetolil area, the financial support of the National Geographic Society for the Laetolil project, and the laboratory facilities provided by the Trustees of the National Museums of Kenya are gratefully acknowledged. Thanks go to Mr. P. Kimit- ta for photographic assistance, to Ms. C. Weiler for the drawings, and Mr. J. MacDonald for technical assistance. The author's foreign travel and expenses were supported by the University of Michigan Geological Sciences Department Scott Turner Fund, the Rackham Fund, and the N.S.F. Graduate Fellowship Program. Special thanks are extended to Doctor Alan Walker for his critical review of the descriptions.

\section{LITERATURE CITED}

Leakey, M. D., R. L. Hay, G. H. Curtis, R. E. Drake, M. K. Jackes and T. D. White 1976 Fossil Hominids from the Laetolil Beds. Nature, 262: $460-466$.

Leakey, R. E. F., J. M. Mungai and A. C. Walker 1971 New australopithecines from East Rudolf, Kenya. Am. J. Phys. Anthrop., 35: 175-186.

Robinson, J. T. 1956 The Dentition of the Australopithecinae. Transvaal Museum Memoir 9. p. 1-179.

Tobias, P. V. 1967 Olduvai Gorge Volume II. The Cranium of Australopithecus (Zinjanthropus) boisei. Cambridge University Press, Cambridge. p. 1-252.

Weidenreich, F. 1936 The mandibles of Sinanthropus pekinensis: a comparative study. Palaeont. Sin. Ser. D.; VII-3, 1-132.

Weinert, H. 1950 Über die neuen Vor - und Frühmenschenfunde aus Afrika, Java, China und Frankreich. Zeit. Morph. u. Anthrop., 42: 113148 .

Note added in proof: After this paper was written, Doctor Reiner Protsch kindly allowed the author to examine the original Garusi maxilla fragment. This was recovered in 1939 by L. Kohl-Larsen and described by Weinert ( 50 ) as the holotype of Meganthropus africanus. The adhering matrix, color, and preservational details of the specimen combine to strongly suggest both derivation from the Laetolil Beds and rough contemporaneity with the numbered hominids described in this paper. 
PLATES 


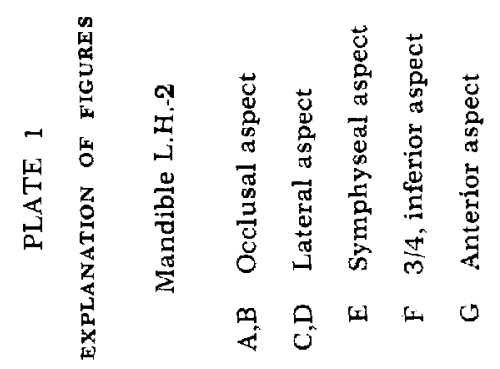



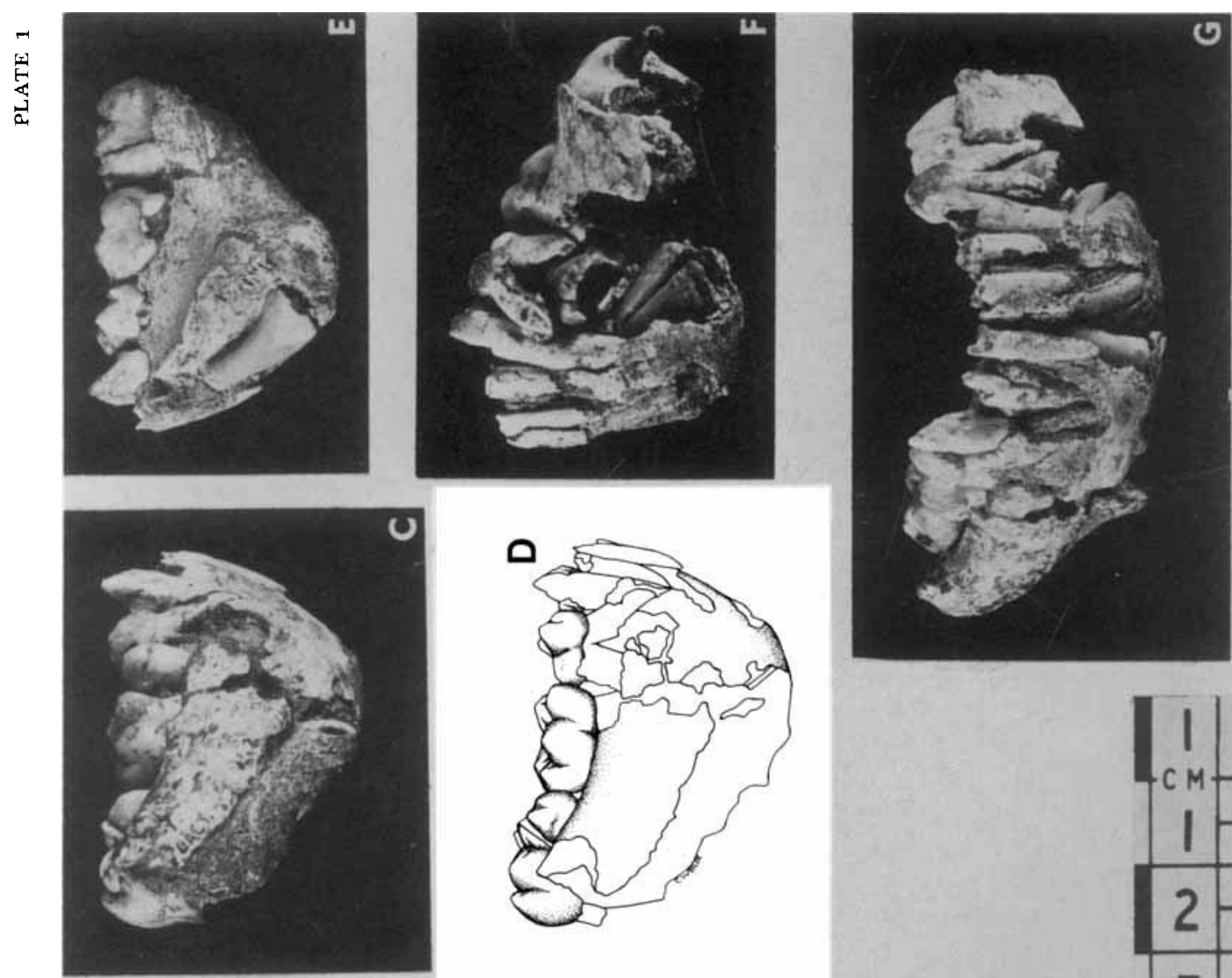

4
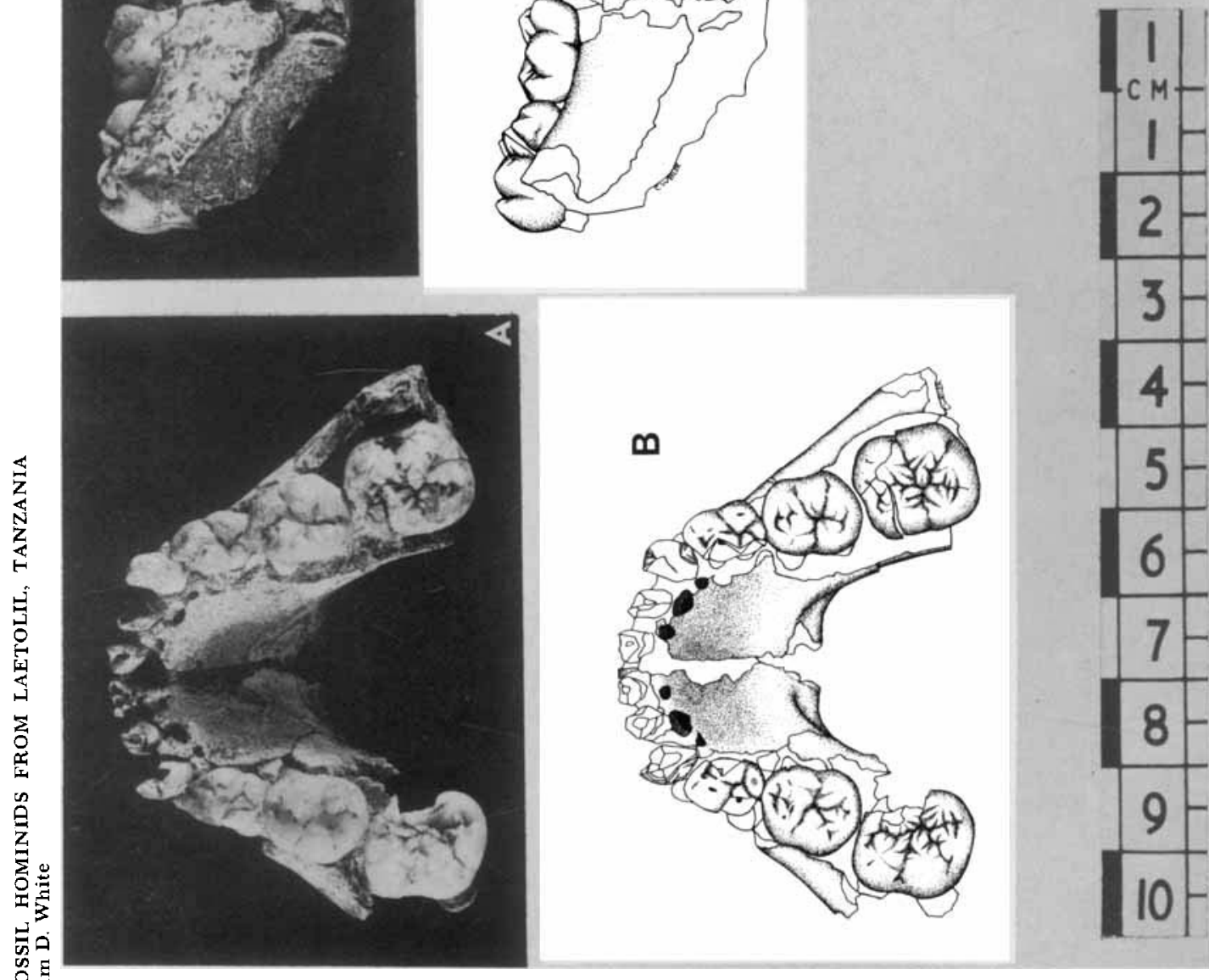

造 


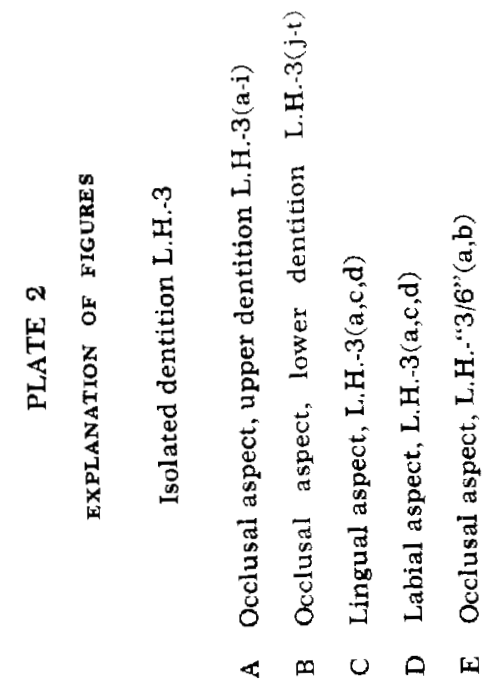




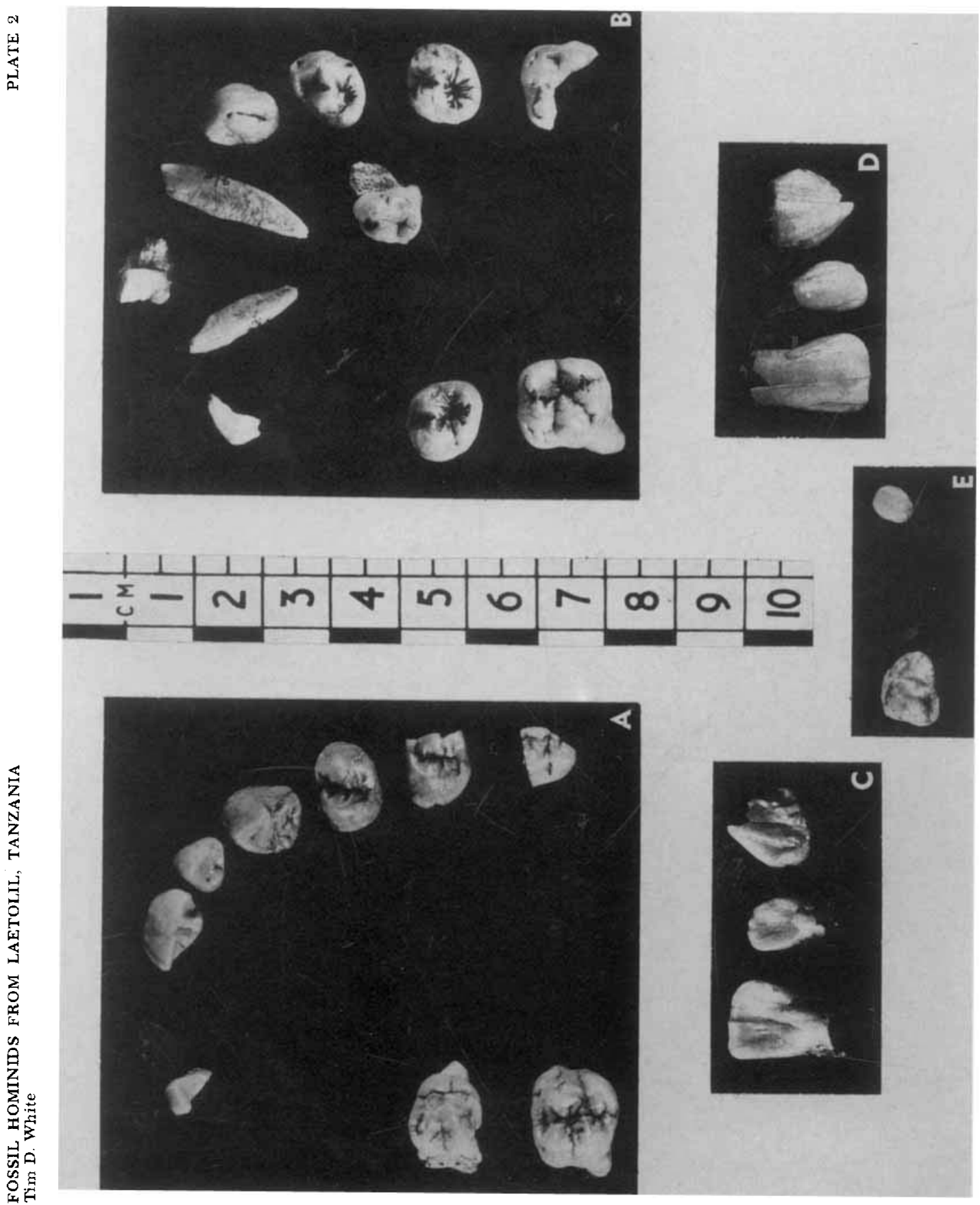




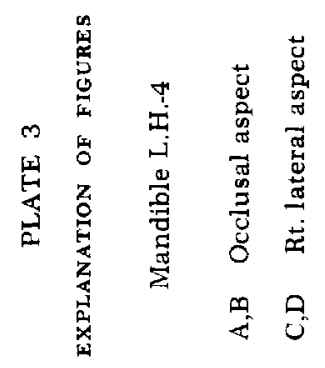


点
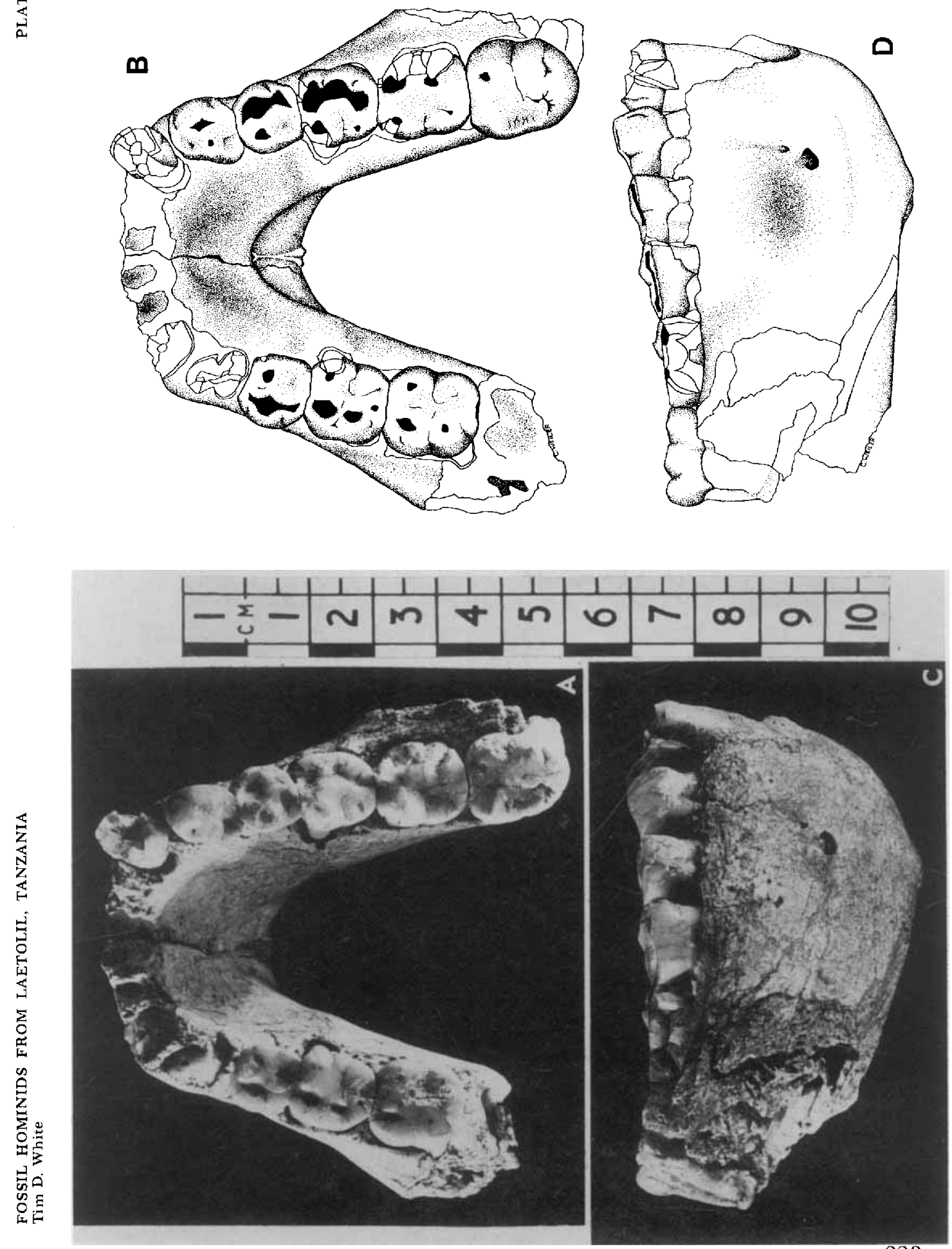


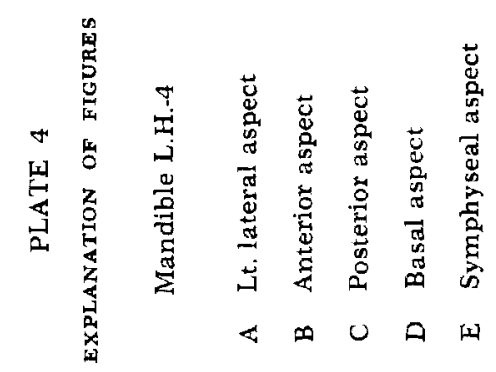



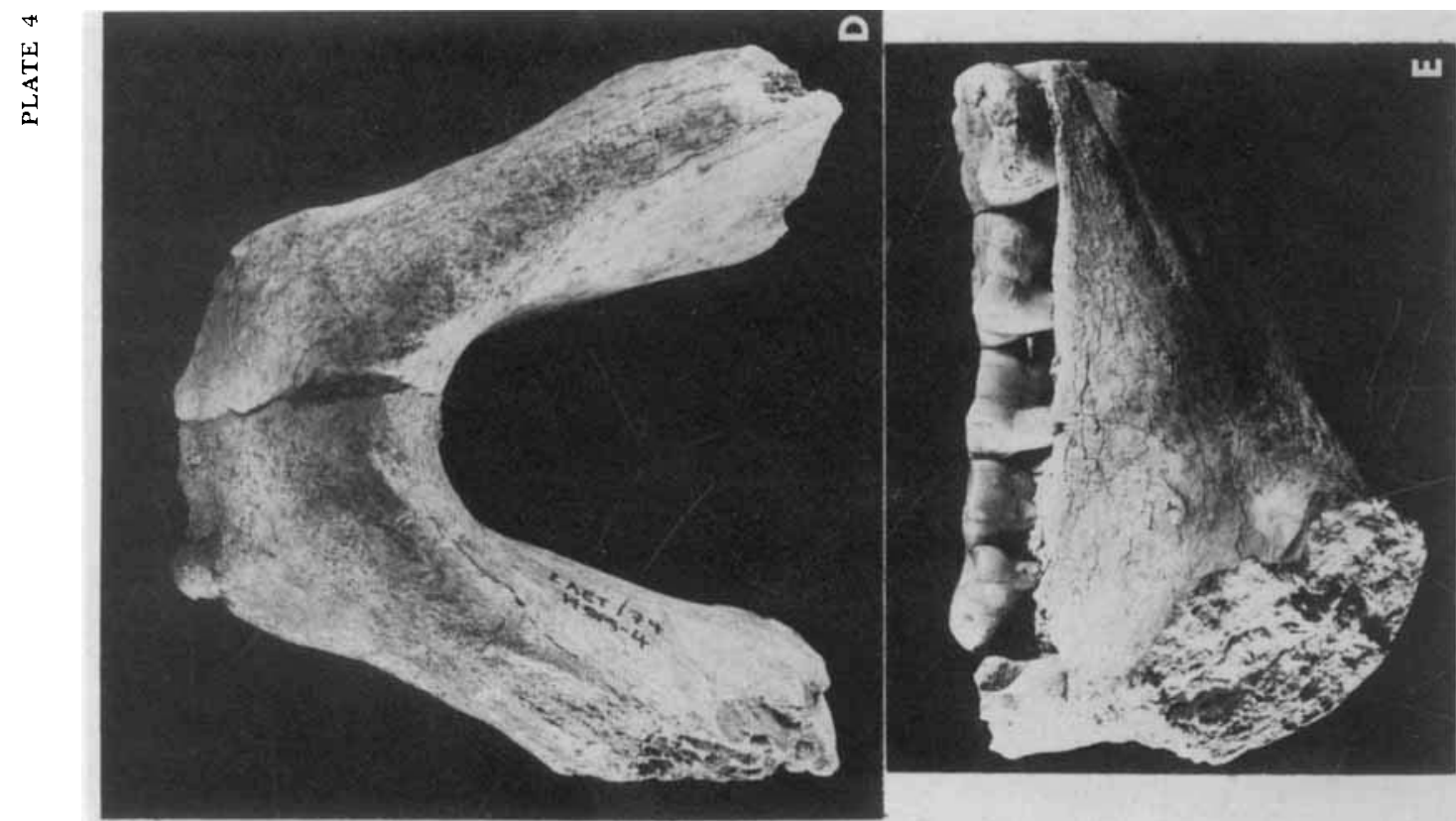

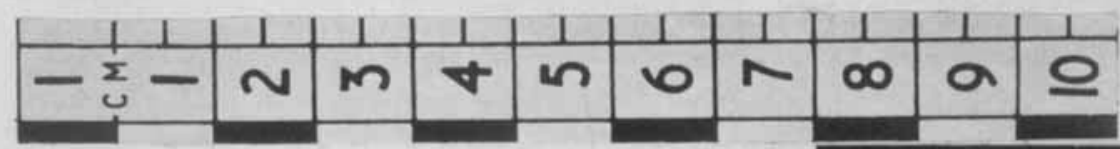
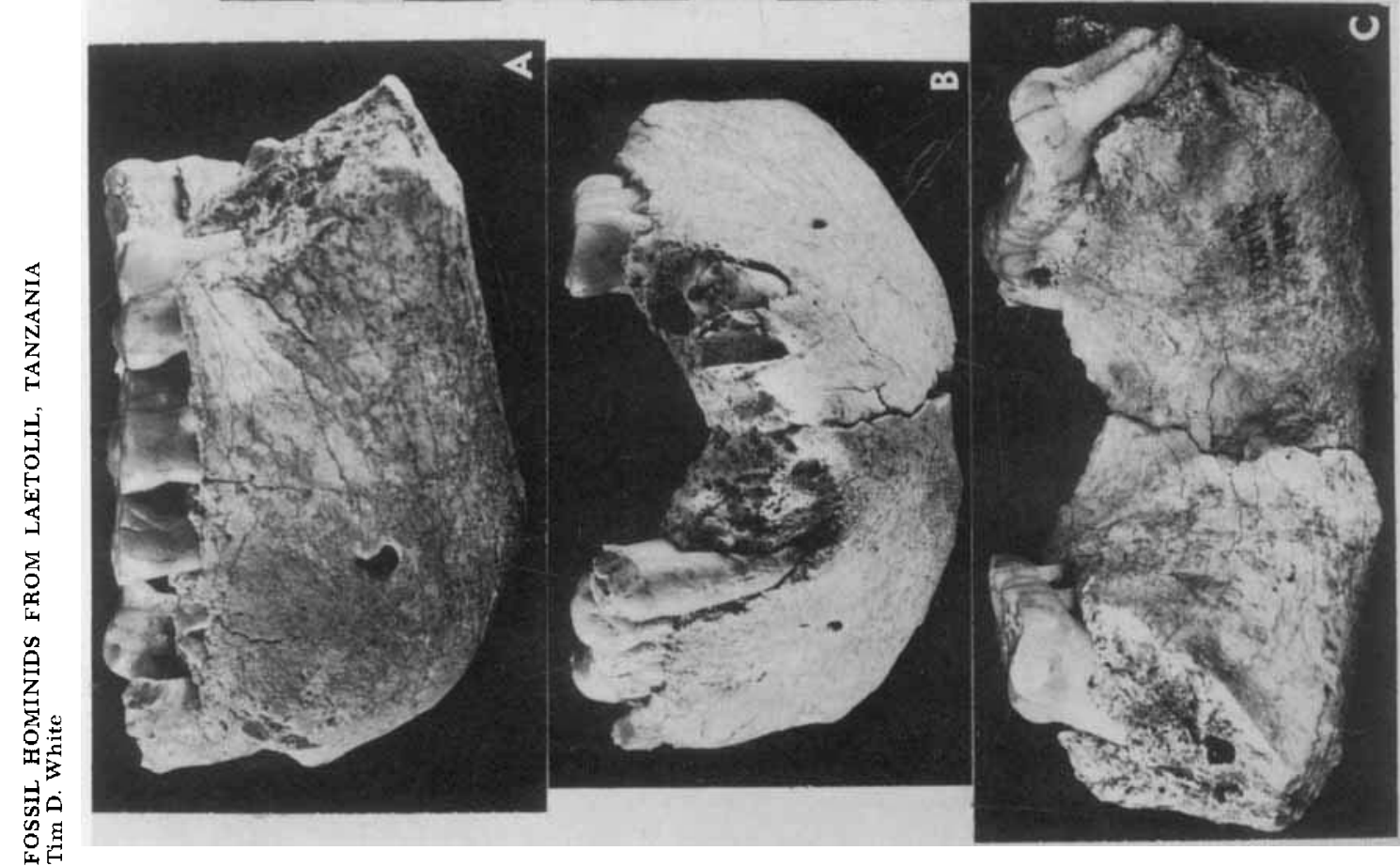


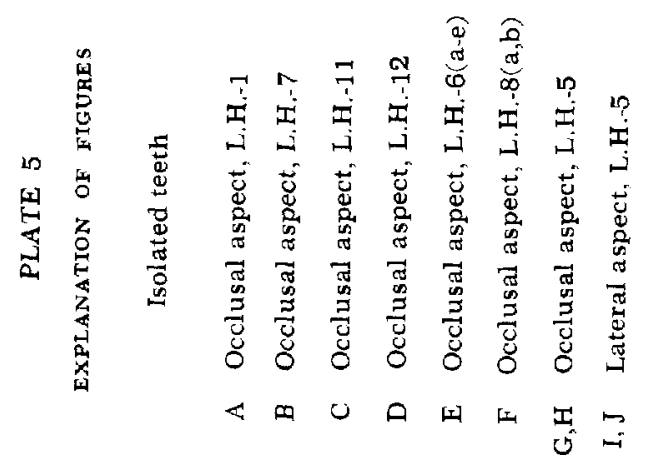



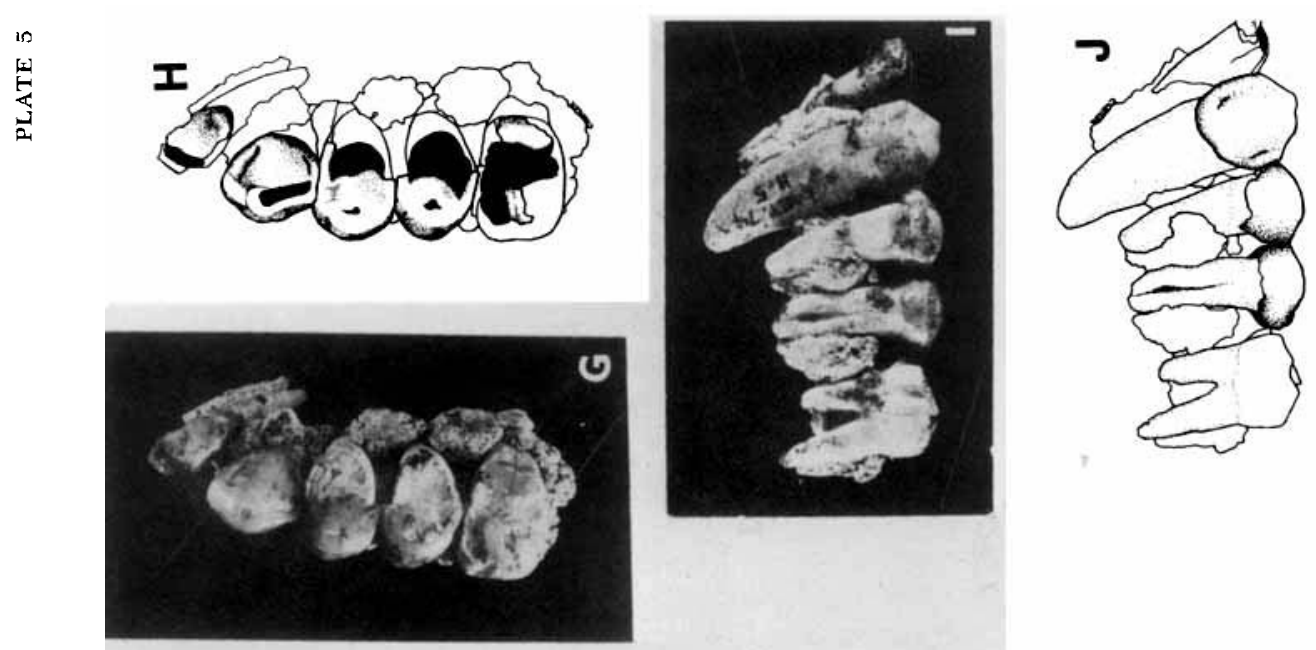

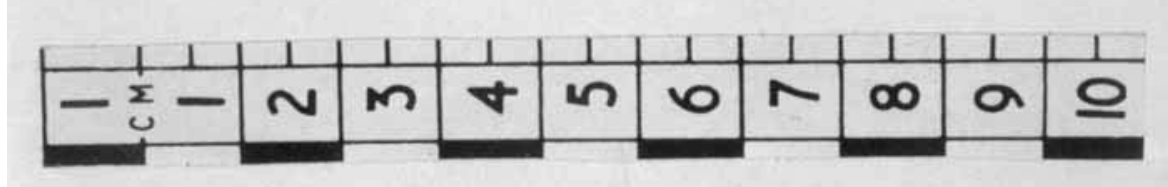

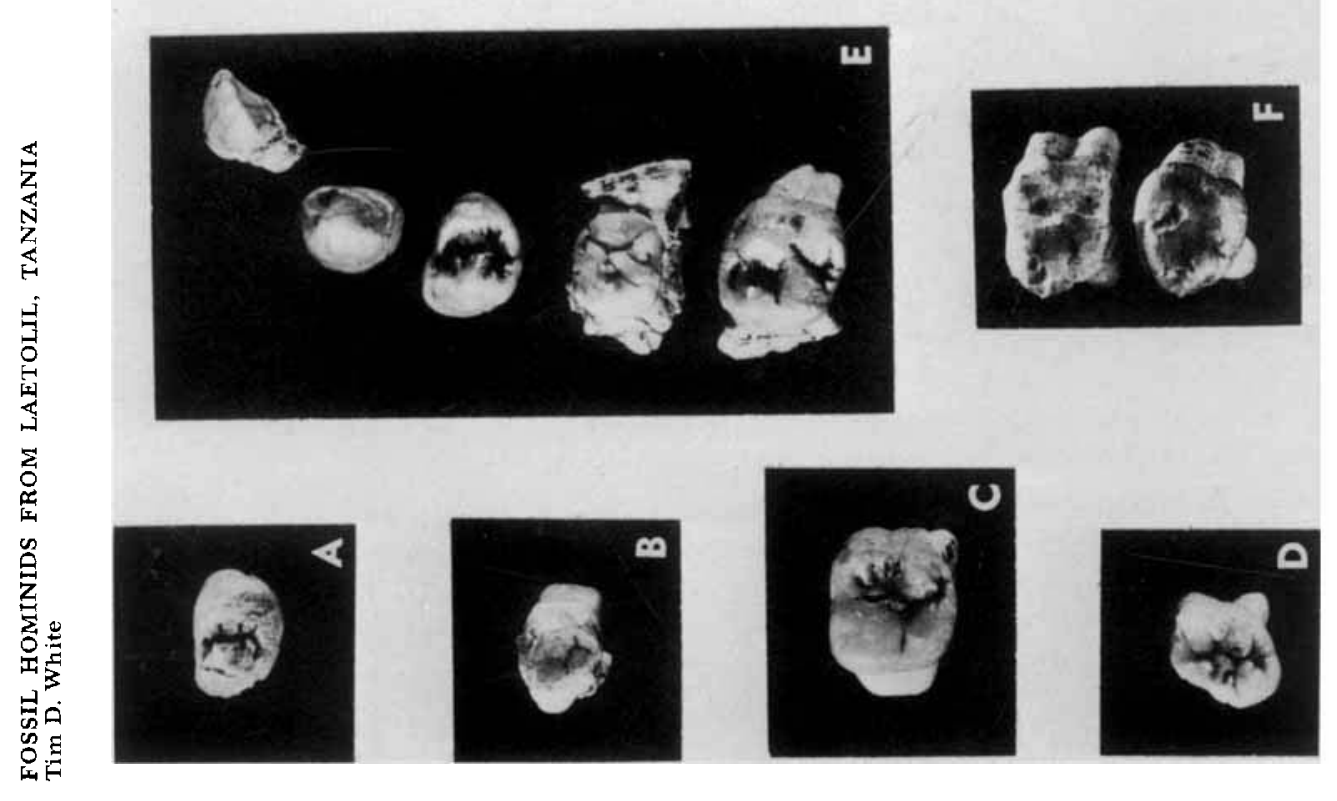




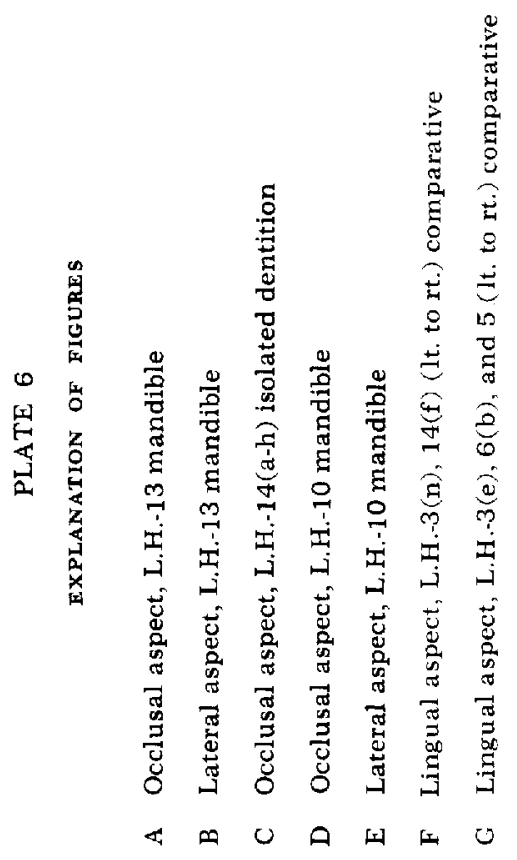



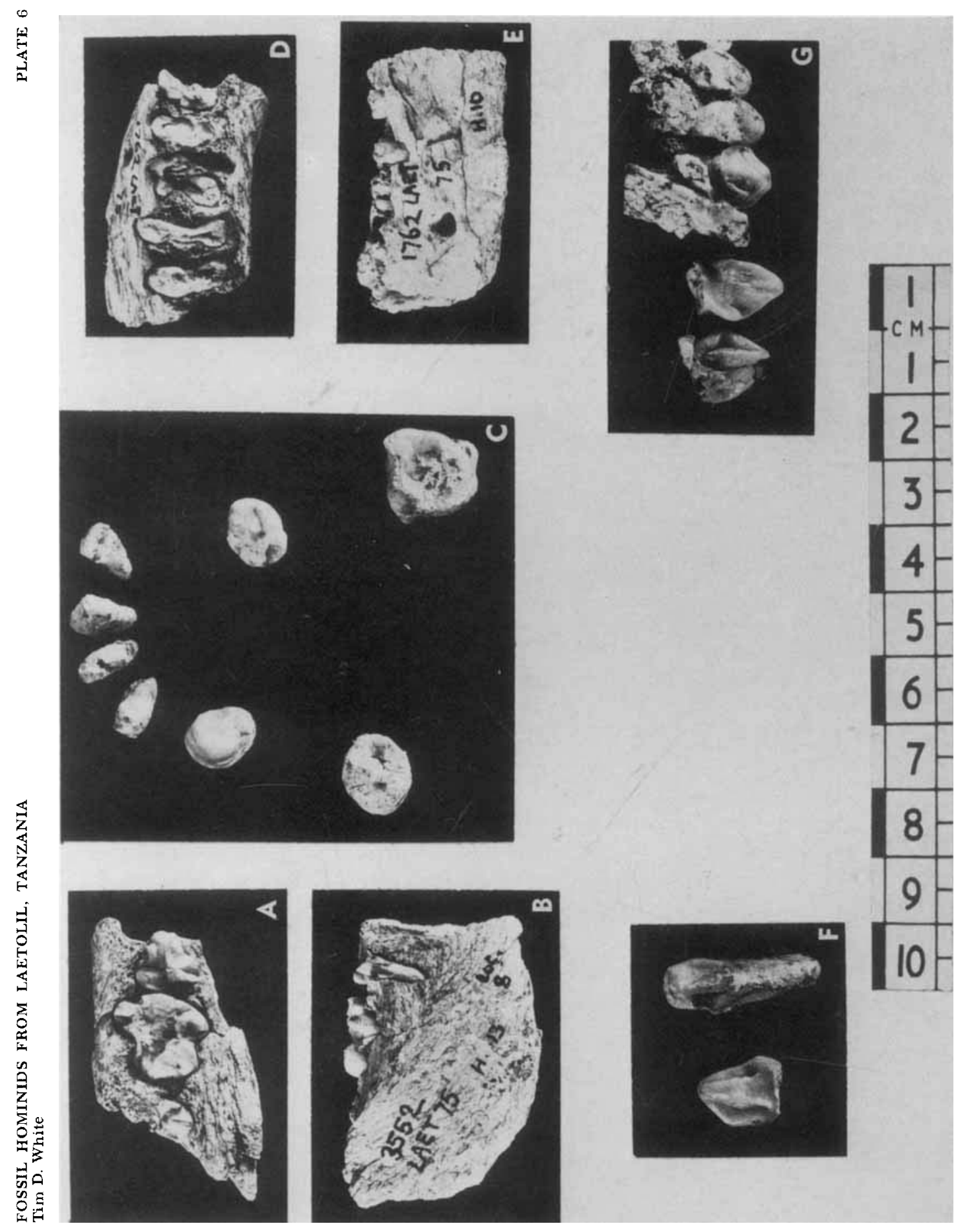